\title{
NEW IDEAS, OLD PROBLEMS? HEATED TOBACCO PRODUCTS - A SYSTEMATIC REVIEW
} \author{
PAULINA MAJEK ${ }^{1}$, and JAN E. ZEJDA ${ }^{1}$ \\ ${ }^{1}$ Medical University of Silesia in Katowice, Katowice, Poland \\ School of Medicine in Katowice, Department of Epidemiology \\ ${ }^{2}$ University of Saskatchewan, Saskatoon, Canada \\ College of Medicine, Canadian Centre for Health and Safety in Agriculture \\ ${ }^{3}$ University of Saskatchewan, Saskatoon, Canada \\ College of Medicine, Department of Medicine \\ ${ }^{4}$ Medical University of Silesia in Katowice, Katowice, Poland \\ School of Medicine in Katowice, Department of Pneumonology
}

MATEUSZ JANKOWSKI ${ }^{1}$, GRZEGORZ M. BROŻEK ${ }^{1}$, JOSHUA LAWSON²,3, SZYMON SKOCZYŃSKI ${ }^{4}$,

\begin{abstract}
Heated tobacco products (HTPs) are a form of nicotine delivery intended to provide an alternative to traditional cigarettes. The aim of this systematic review was to present the current state of knowledge on HTPs with an emphasis on the potential impact of HTP use on human health. During the preparation of this systematic review, the literature on HTPs available within Medline/PubMed, EMBASE, CINAHL, ScienceDirect, and Google Scholar was retrieved and examined. In the final review, 97 research papers were included. The authors specifically assessed the construction and operation of HTPs, as well as the chemical composition of HTP tobacco sticks and the generated aerosol, based on evidence from experimental animal and cellular studies, and human-based studies. Heated tobacco products were found to generate lower concentrations of chemical compounds compared to traditional cigarettes, except for water, propylene glycol, glycerol, and acetol. The nicotine levels delivered to the aerosol by HTPs were $70-80 \%$ as those of conventional combustion. The results of in vitro and in vivo assessments of HTP aerosols revealed reduced toxicity, but these were mainly based on studies sponsored by the tobacco industry. Independent human-based studies indicated that there was a potentially harmful impact of the active and passive HTP smoking on human health. Currently, a large body of knowledge on HTP exposures and health effects is provided by the tobacco industry (52\% of identified studies). Based on the available evidence, HTPs produce lower levels of toxic chemicals, compared to conventional cigarettes, but they are still not risk-free. Int J Occup Med Environ Health. 2019;32(5):595-634
\end{abstract}

Key words:

smoking, systematic review, nicotine, tobacco industry, heat-not-burn tobacco products, heated tobacco products

Funding: this study was supported by the Medical University of Silesia (grant No. KNW-1-024/K/7/0).

Received: January 16, 2019. Accepted: July 12, 2019.

Corresponding author: Grzegorz M. Brożek, Medical University of Silesia in Katowice, School of Medicine in Katowice, Department of Epidemiology, Medyków 18, 40-752 Katowice, Poland (e-mail: gbrozek@sum.edu.pl). 


\section{INTRODUCTION}

Heated tobacco products (HTPs) are a form of nicotine delivery intended to provide an alternative to traditional cigarettes. These products were introduced for the first time in 1988, in the USA, as "Premier" from R.J. Reynolds [1]. As in the case of electronic cigarettes, this technology initially did not gain wide popularity and was discontinued shortly after its introduction. Recently, the tobacco industry has made another attempt to introduce HTPs to the market [2-6]. In 2014, a heated tobacco system from Philip Morris International (PMI), marketed as IQOS (I-Quit-OrdinarySmoking), was introduced [3-6]. Other tobacco companies introduced their own HTPs in 2016. British American Tobacco (BAT) created an HTP called "glo" [6], while a heated tobacco and e-cigarette hybrid was developed by Japan Tobacco (JT) and marketed as "Ploom TECH" [6].

The heated tobacco smoking technology is based on a unique electronic method of heating to generate aerosols from tobacco sticks. Tobacco heating systems operate at lower temperatures $\left(240-350^{\circ} \mathrm{C}\right)$ than conventional cigarettes $\left(>600^{\circ} \mathrm{C}\right)[7]$.

The IQOS tobacco heating system includes a "pen-shaped" electronically controlled heating element (holder) and a portable charger for recharging the holder [4,8]. The IQOS uses a metal blade to penetrate tobacco sticks (called "HEETS"), thus heating tobacco from inside the stick up to $350^{\circ} \mathrm{C}[8,9]$. The heating holder supplies heat for 6 min and allows up to 14 puffs. After this time, the holder needs to be recharged [8]. Glo operates in a similar manner [9]. The device looks like a small simple box with an oval socket in the periphery on top, where the tobacco stick is placed. After pressing the button in the middle of the device, the tobacco stick (called "Kent Neostiks") is heated to $240^{\circ} \mathrm{C}$ through a metal heating element surrounding the tobacco stick [10,11]. A single charge lasts for up to 30 smoking sessions [11].

A slightly different heating technology is implemented by Ploom TECH [6,12]. In this case, the nicotine-containing aerosol is generated by heating an inhalation solution (con- taining propylene glycol or glycerol) which passes through a capsule made of granulated tobacco leaves $[12,13]$.

Tobacco companies claim that HTPs are less harmful than traditional cigarettes [14-18]. However, the potential impact of HTP use on human health has not been fully investigated yet.

The prevalence of HTP use has been increasing, especially in highly developed countries such as Japan and Italy $[2,3,5,6]$. Based on the growth of the e-cigarette market in recent years, it is expected that the popularity of HTPs will continue to increase rapidly.

The aim of this systematic review is to examine the current state of knowledge on heated tobacco products. As a part of this process, the authors will:

- review the chemical composition of HTP tobacco sticks;

- review the chemical composition of the aerosol generated during HTP use;

- review evidence from experimental studies on animal and cellular models;

- review evidence from human-based studies;

- describe the prevalence of HTP use. In addition, they will also assess the marketing strategies of the tobacco industry as a way of considering the potential burden of the problem.

\section{MATERIAL AND METHODS}

The authors conducted a systematic review to complete the objectives outlined above. The search was carried out in Medline/PubMed, EMBASE, CINAHL, ScienceDirect, and Google Scholar. Combinations of the following key words: "IQOS," "glo," "Ploom TECH," "heat-not-burn," "heated tobacco," "novel tobacco products," with "aerosol," "chemical composition," "cells," "nicotine," "safety," "health effects," "toxicity," "secondhand exposure," "addiction," "frequency of use," "marketing" and "safety" were used. Potentially relevant articles were selected based on their titles and abstracts. If an article was considered potentially relevant, the full paper 
was printed for review. Reference lists from the selected articles were checked for publications that may have been missed in the initial search. Manufacturer websites regarding data about the mode of use and all registration details were also reviewed. Finally, websites of leading health organizations were reviewed to identify their positions on HTPs. The final search was conducted on December 31, 2018.

Articles were eligible to be included in the review if they were original, peer-reviewed articles, published in English. There was no limit regarding the time that had passed since publication other than the final date being December 31, 2018. Review and personal opinion papers were excluded. Papers that focused on other forms of smoking, such as electronic cigarettes, smokeless tobacco such as chewing tobacco or snus, shisha, and hookah, were also excluded. The to- bacco industry is also working on a new form of HTPs called carbon heated tobacco products (CHTPs) [19]. Due to the different mode of operation, the early phase of the products (no general product sales), and the limited amount of research related to these products, they were not analyzed in detail in this review. Nevertheless, carbon-covered tobacco products are an alternative form of nicotine delivery and will require close monitoring in the future.

The literature search and selection of articles were performed independently by 2 researchers. A comparison of the search results was made and, where there was a discrepancy, inclusion decisions were based on a consensus following discussion.

The search process that led to the identification of 289 potential articles is summarized in Figure 1. Of these, 138 were
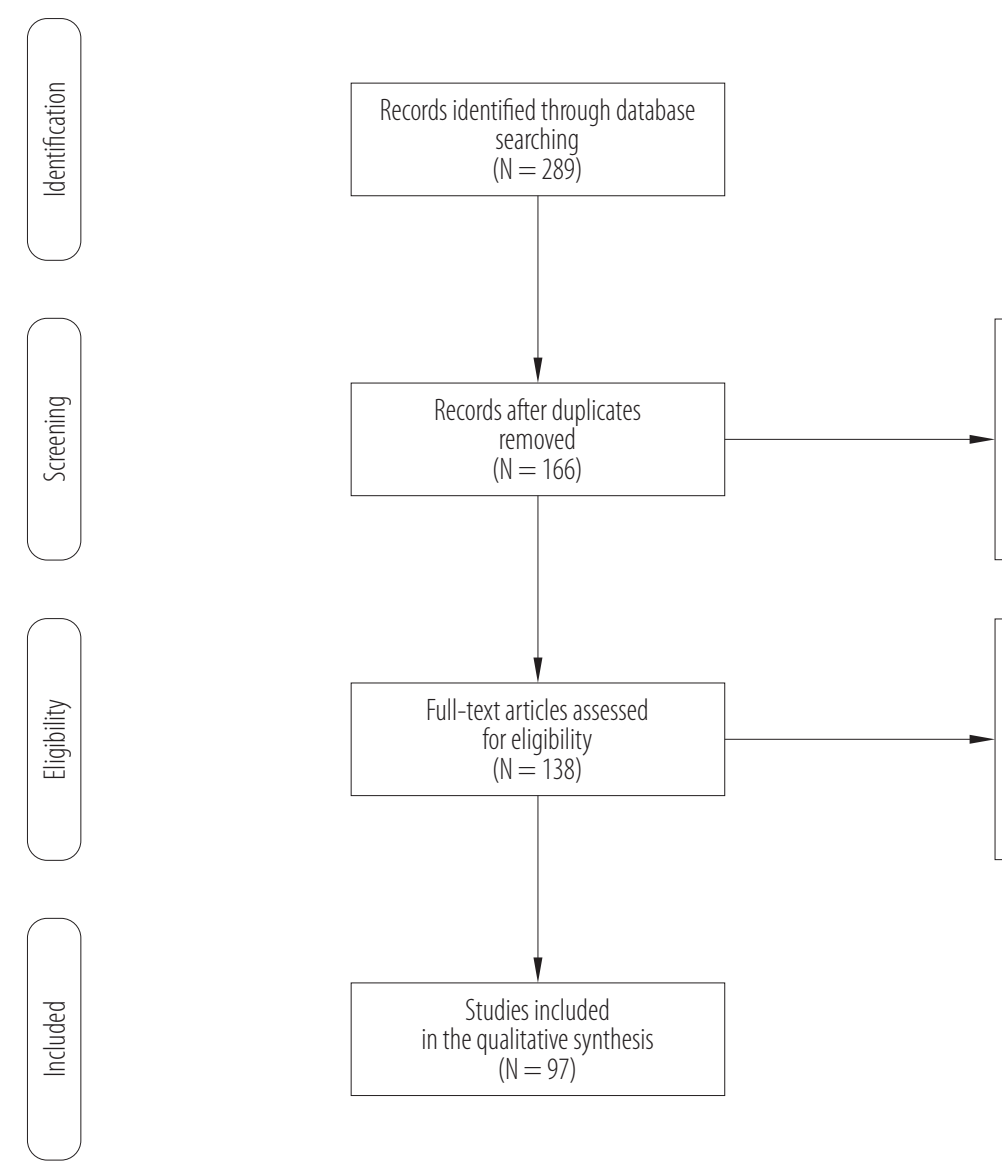

\section{Records excluded \\ $(\mathrm{N}=75)$}

49 studies about e-cigarette, chewing tobacco snus, shisha, or hookah

9 conference abstracts

12 studies not in English

5 studies on carbon heated tobacco products

Figure 1. PRISMA Flow Diagram [105] 
considered to be relevant after screening the titles and abstracts. After full-article review, 97 papers were considered eligible and included in this review. Review papers, commentaries and opinions as well as studies on the validation of selected analytical methods were excluded from the final analysis.

For each paper, the funding source and authors' conflict of interest declarations were analyzed. In this review, of the 97 identified papers, $50(52 \%)$ had a potential conflict of interest. The presence of a conflict of interest in all papers regarding the toxicity of HTP aerosols may indicate a potential risk of bias. To help assess this phenomenon, tobacco industry sponsored papers were separated from independent studies and visibly marked in this review. The authors also completed a brief sensitivity analysis summarizing the results of the tobacco company funded studies and independently funded studies separately.

\section{RESULTS}

\section{Chemical composition of tobacco sticks}

Similar to conventional cigarettes, heated tobacco products use real tobacco. Tobacco sticks are available in multiple flavors $[10,20]$. Among the multiple HTP tobacco sticks available on the market, only IQOS tobacco sticks were tested in detail $[8,9,21]$. The chemical composition of HEETS tobacco sticks includes processed tobacco, water, glycerin, guar gum, cellulose fibers, a polymer-film filter, and a cellulose-acetate mouthpiece filter [22]. According to the manufacturer data, the IQOS tobacco stick contains smaller amounts of tobacco compared to conventional cigarettes [20]. Independent studies by Farsalinos et al. [9] and Bekki et al. [21] showed that IQOS sticks contained 70-80\% of the nicotine concentration found in conventional cigarettes. Davis et al. evaluated the performance of the IQOS system under various conditions [8]. The use of 1 IQOS stick left a significant amount of debris, fluid, and fragments of cast-leaf in the device holder. Follow- ing the manufacturer recommendations, cleaning of the device after each 20 tobacco sticks seems to be crucial to provide proper thermal regulation [8]. Moreover, Davis et al. showed that the heat produced by the device was enough to cause charring of the tobacco plug via pyrolysis and melting of the polymer-film filter [8]. This independent observation is in contrast to the manufacturer's claim that pyrolysis is minimized during IQOS use. Detailed information on the chemical composition of HTP tobacco sticks is presented in Table 1.

\section{Chemical composition of generated aerosol}

The tobacco industry claims that during HTP use, emissions of toxic chemicals are reduced due to the lower working temperature of the devices [13-15,23,24]. The results of independent studies suggest that toxic compounds are not completely removed from the HTP aerosol and these products are still not risk-free (Table 1) [7,19,25-35].

Uchiyama et al. compared the chemical composition of the aerosol from all 3 available heated tobacco products: IQOS with 4 different heat sticks, glo with 3 different heat sticks, and Ploom TECH with 3 different tobacco capsules, with smoke generated from 2 different reference cigarettes [7]. Water accounted for $75-85 \%$ of the total gaseous and particulate matter generated during IQOS and glo use, compared to $17-27 \%$ in the smoke from traditional cigarettes [7]. Heated tobacco products generated fewer chemical compounds compared to traditional cigarettes, except for water, propylene glycol, glycerol, and acetol, where the concentration in mainstream smoke was higher in heated tobacco than in traditional cigarettes [7,27]. Numerous studies, both independent and industry sponsored, have shown that the levels of nicotine contained in the aerosol released by HTPs (both regular and menthol versions) were $70-80 \%$ as those of conventional combustion cigarettes [15,27,29,33,36]. Farsalinos et al. reported that HTPs delivered nicotine to the aerosol at levels higher than e-cigarettes [9]. 


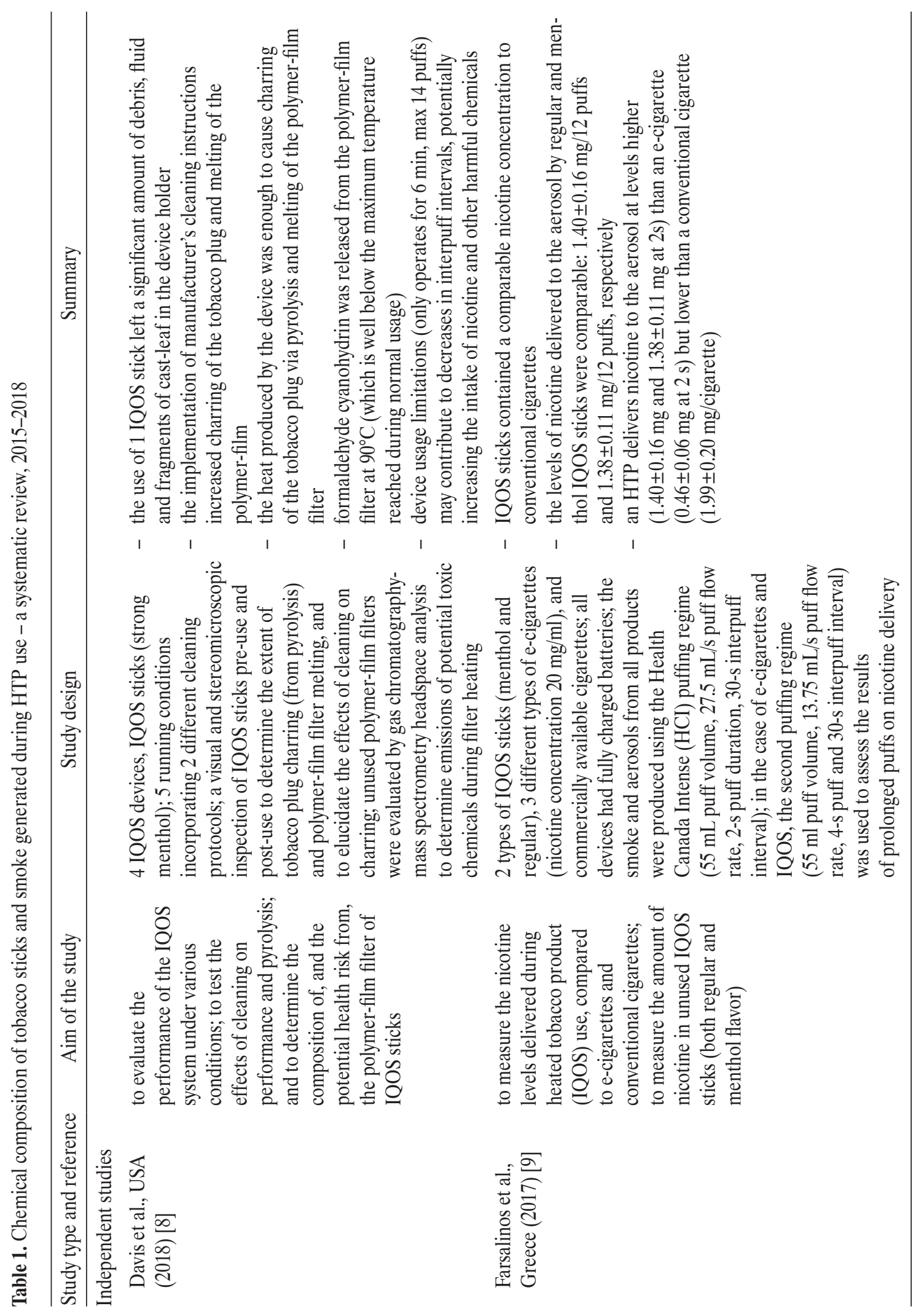




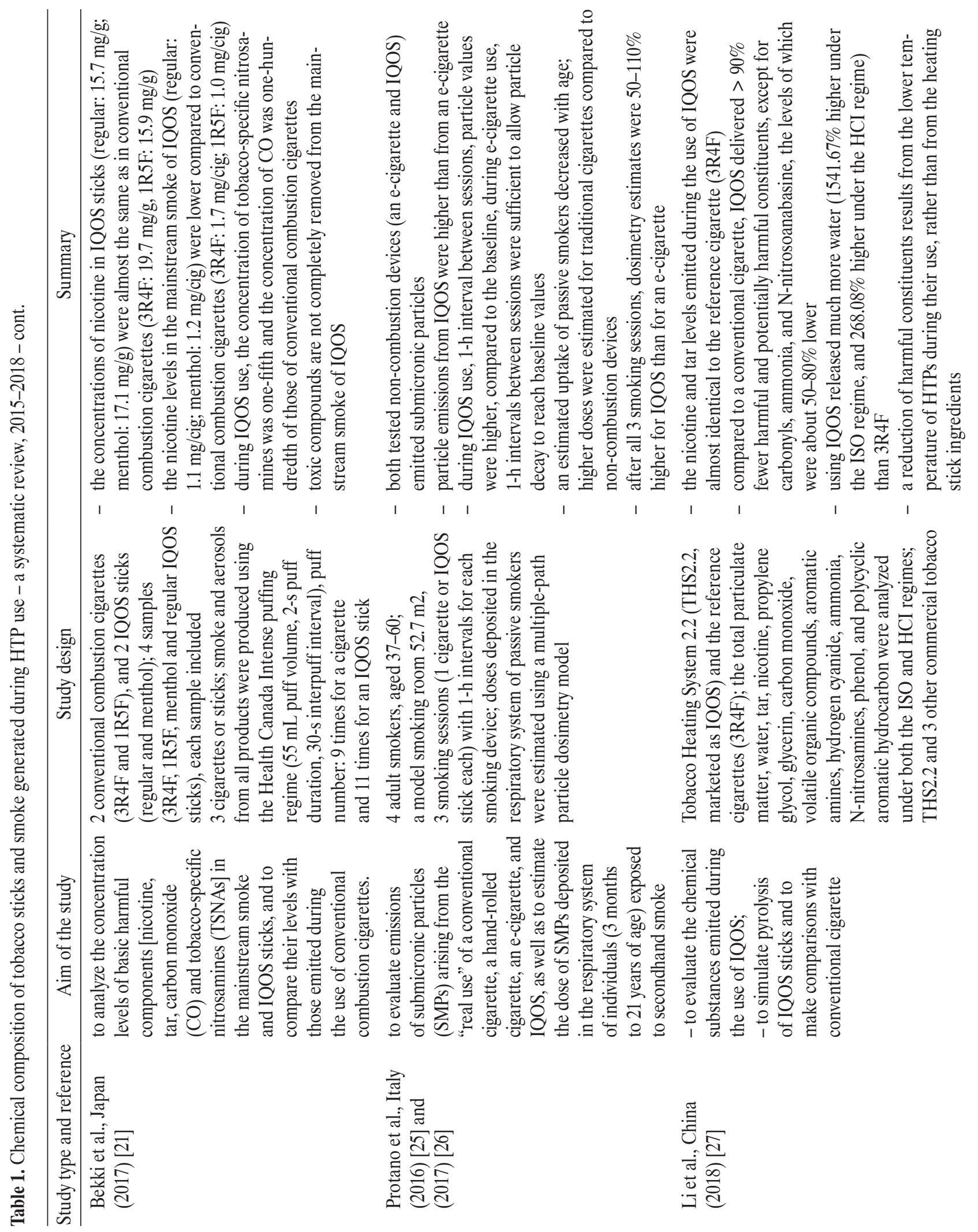




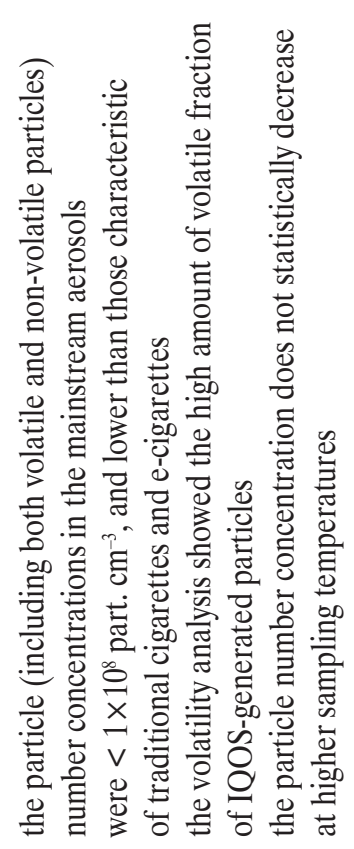

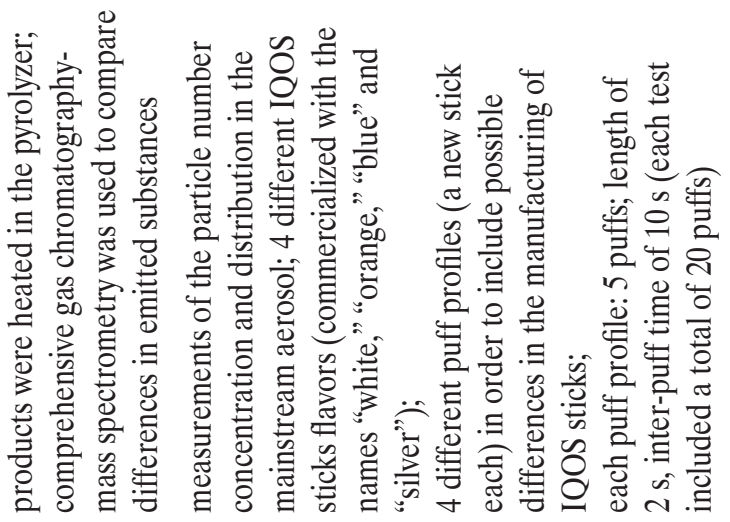
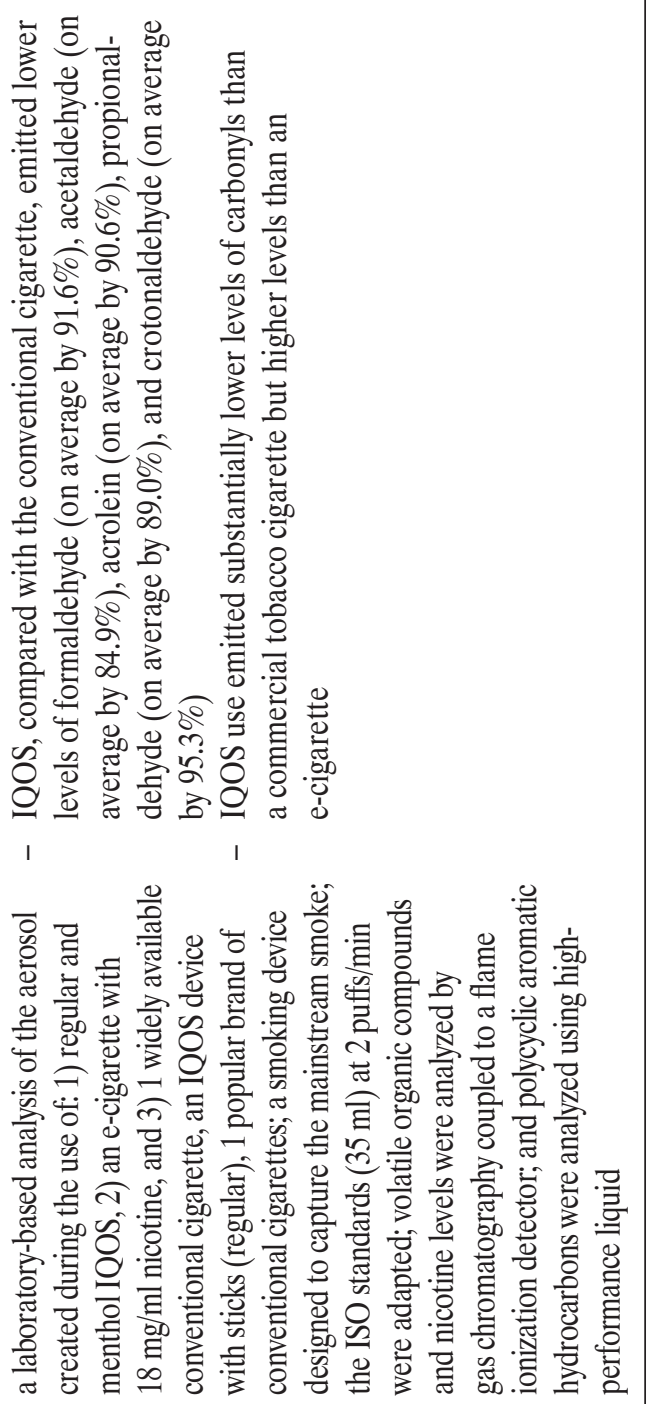

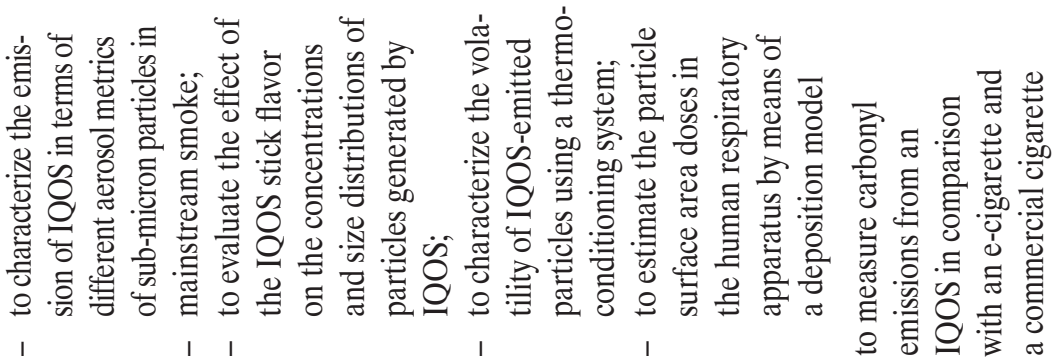

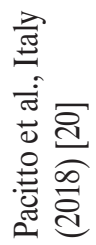

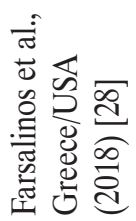




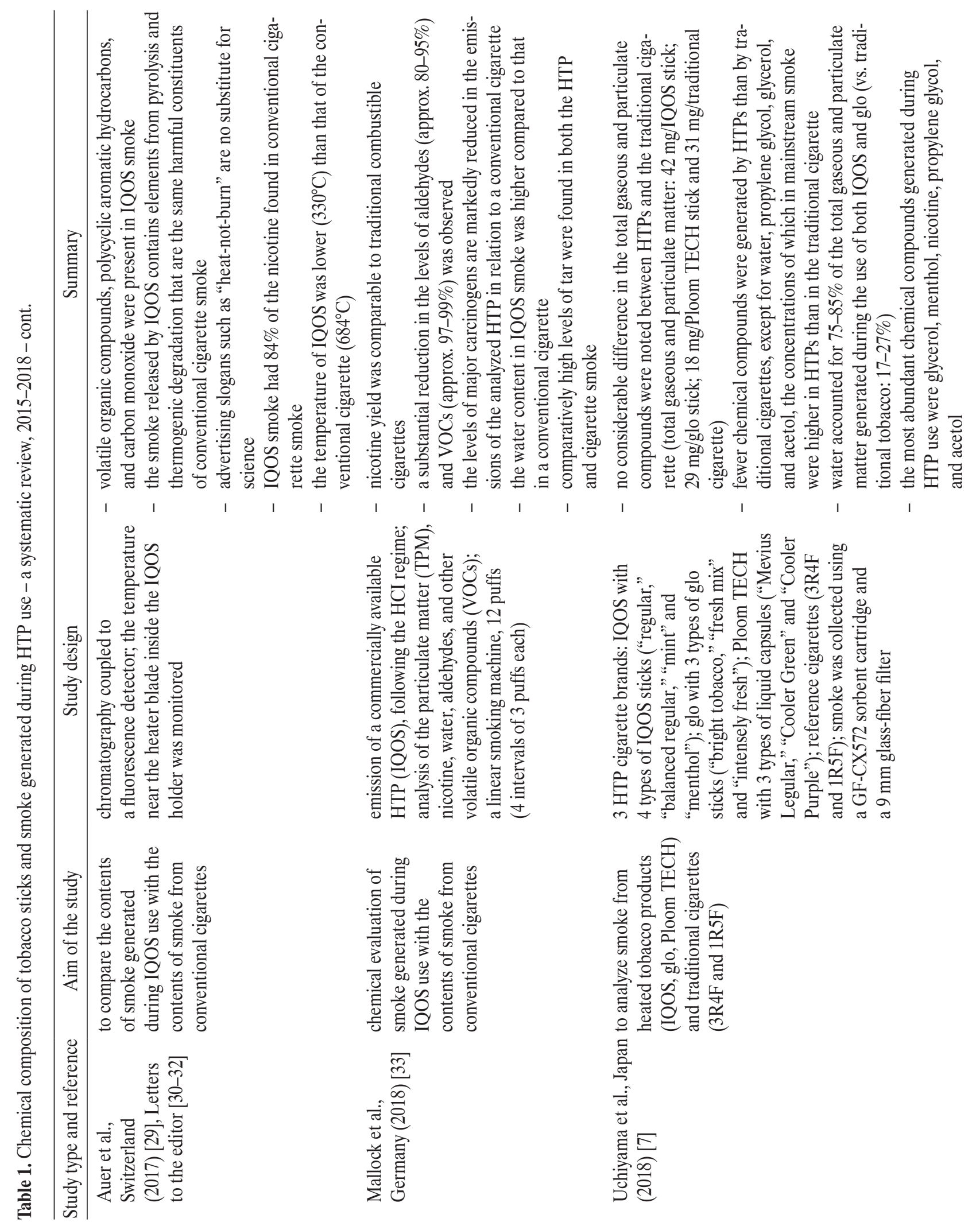



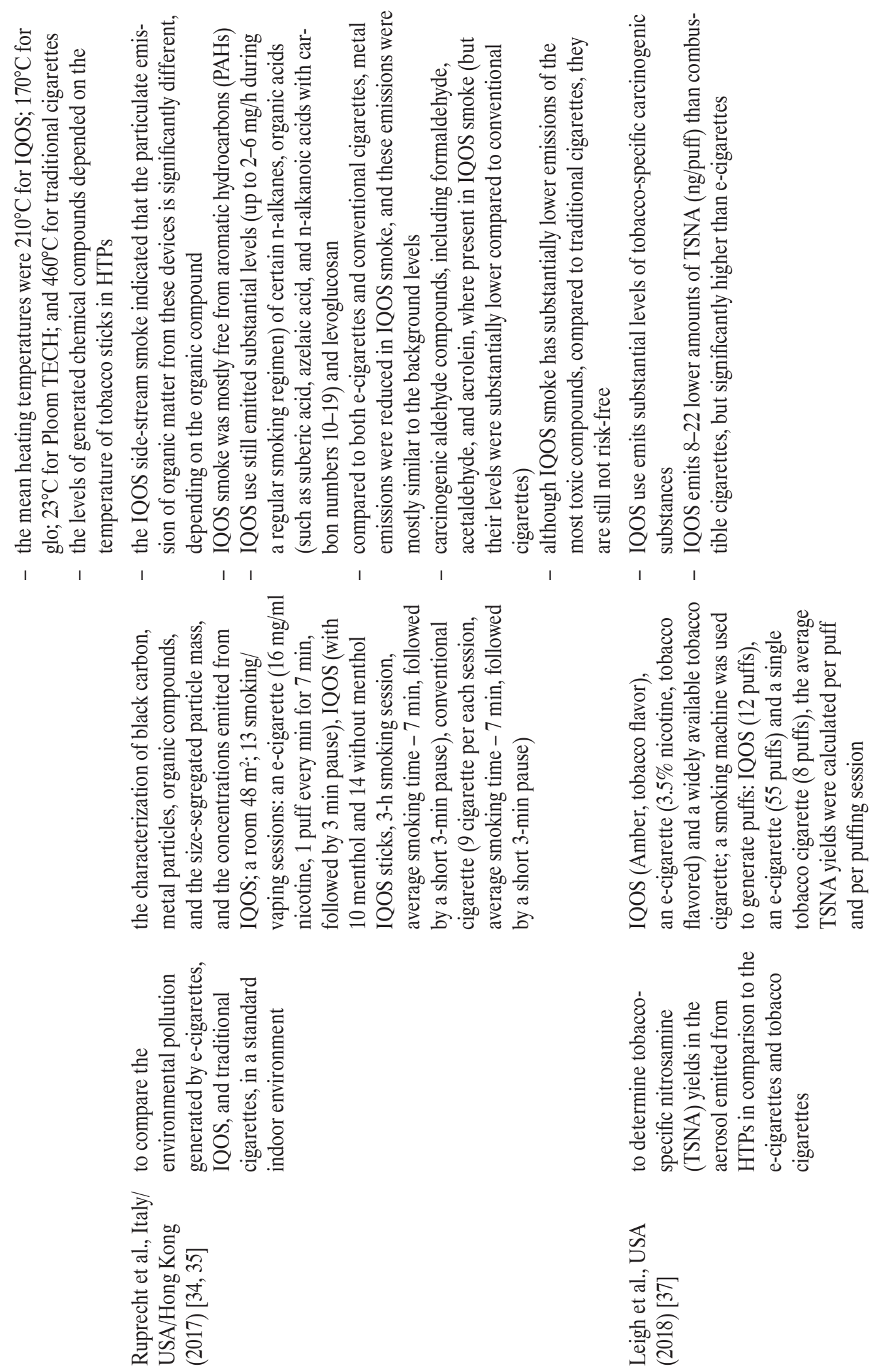


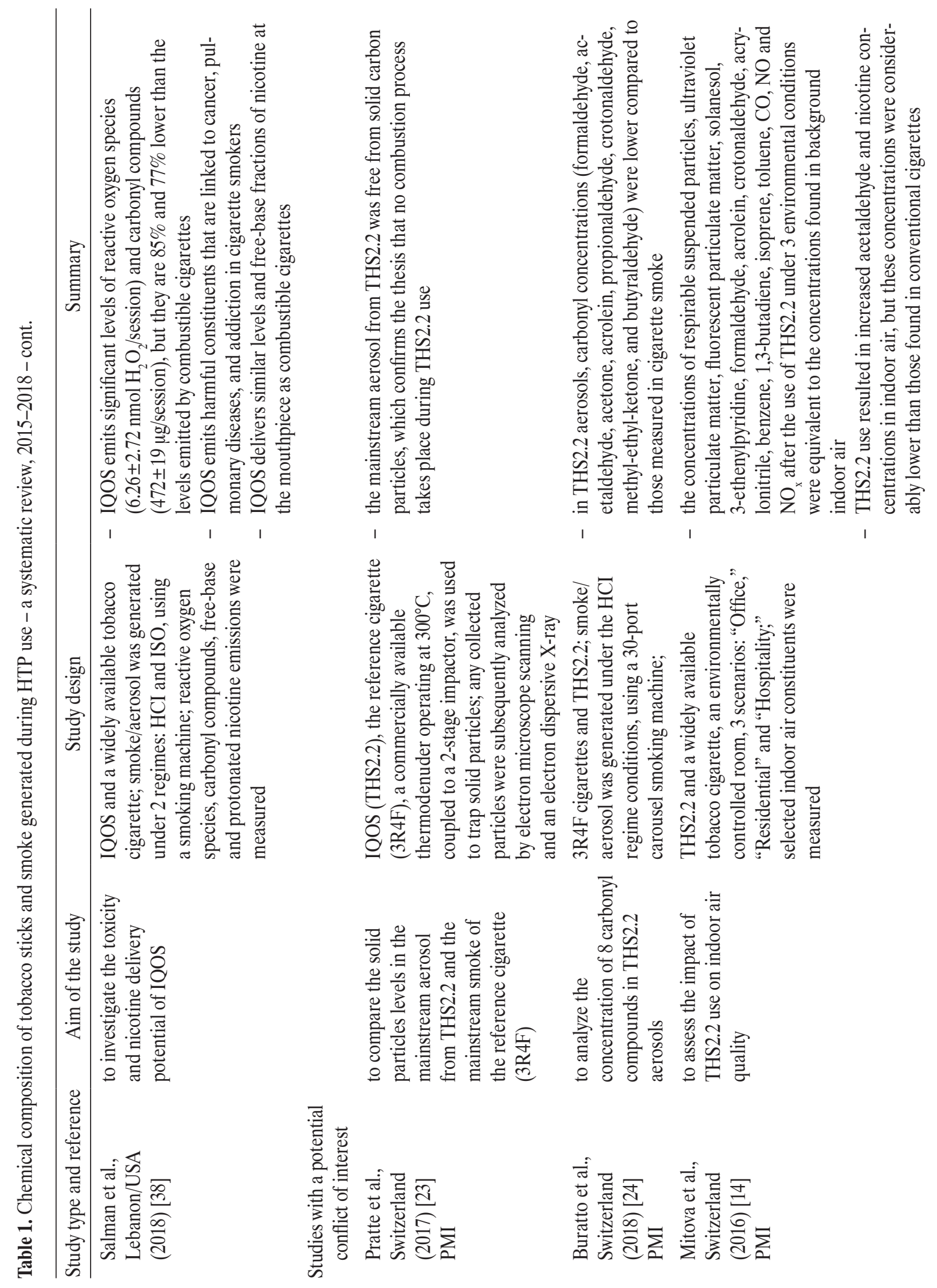



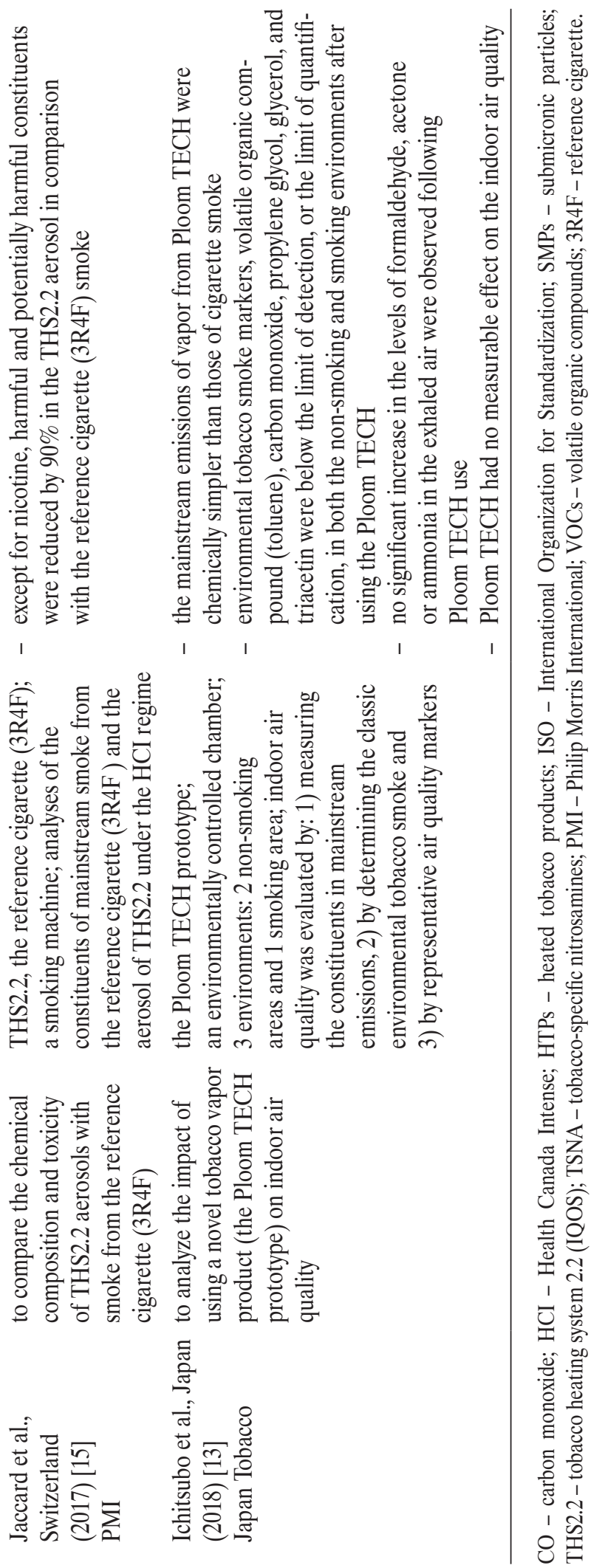

The tobacco industry claims that the aerosol formed during the heating process has around 90-95\% lower levels of toxicants than conventional cigarette smoke [13-15,23,24]. This was partially confirmed by independent studies [27,28]. Li et al. reported that, compared to conventional cigarettes, IQOS delivered a > 90\% lower concentration of harmful and potentially harmful constituents (HPHCs) except for carbonyls, ammonia, and N-nitrosoanabasine, where the levels were about 50-80\% lower [27]. Farsalinos et al. showed that IQOS use emitted substantially lower levels of carbonyls than a commercial cigarette but higher levels than an e-cigarette [28]. Mallock et al. observed substantially lower levels of aldehydes (approx. 80-95\%) and volatile organic compounds (approx. 97-99\%) in the IQOS aerosol compared to cigarette smoke [33]. Pacitto et al. also showed lower volatile and non-volatile particle concentrations in the mainstream IQOS aerosols compared to traditional cigarette smoke [20].

Protano et al. compared the emission of submicronic particles (SMPs) from IQOS and e-cigarettes [25,26]. Both devices emitted SMPs but the particle emissions from IQOS were higher than those from e-cigarettes. Ruprecht et al. noted that the IQOS aerosol was free from metal emissions, in contrast to cigarette and e-cigarette aerosols [34,35]. However, toxic compounds were not completely removed from the heated tobacco aerosol [15]. Li et al. and Mallock et al. showed that IQOS emitted comparable levels of tar to the reference cigarette [27,33]. Bekki et al. observed that the concentration of tobaccospecific nitrosamines were one-fifth of those of conventional cigarettes [21]. Leigh et al. also observed that IQOS emitted lower amounts of tobacco-specific nitrosamines than combustible cigarettes, but a significantly higher amount than e-cigarettes [37]. Salman et al. reported that the use of IQOS emitted significant levels of reactive oxygen species and carbonyl compounds, but these were still $85 \%$ and $77 \%$ lower than the levels emitted by combustible cigarettes [38]. 
Controversial results were presented by Auer et al. who showed that in the IQOS aerosol, volatile organic compounds, polycyclic aromatic hydrocarbons, and carbon monoxide were detected [29]. Moreover, the smoke released during the use of IQOS contained elements from pyrolysis and thermogenic degradation, similar to the harmful constituents of conventional cigarette smoke [29]. These findings significantly differed from those presented by the tobacco industry and gave rise to heated discussions among the experts [30-33]. Independent experts [31] and industry representatives [32] concluded that the results presented by Auer et al. could be misinterpreted due to the absence of a standardized protocol for emission generation and specifically validated analytical measurements. Some authors suggest that, even without such combustion as in the case of traditional cigarettes, HTPs still release harmful compounds which can then expose bystanders $[25,26,34,35]$. Ruprecht et al. showed that IQOS emitted detectable and substantial levels (up to $2-6 \mathrm{mg} / \mathrm{h}$ during a regular smoking regimen) of several organic compounds, including n-alkanes, organic acids, and aldehyde species such as formaldehyde, acetaldehyde, and acrolein $[34,35]$. Protano et al. estimated the dose of submicronic particles deposited in the respiratory system of individuals exposed to secondhand smoke from a combustible cigarette, an e-cigarette, and IQOS [25,26]. The highest doses were reported to originate from combustible cigarettes compared to non-combustion devices. However, the dosimetry estimates were $50-110 \%$ higher for IQOS than for e-cigarettes [25,26]. Although the IQOS aerosol has substantially lower emissions of toxic compounds compared to traditional cigarettes, it is still a source of passive exposure [25,26].

Based on evidence from studies not sponsored by the tobacco company, in general, the results have shown that HTP use releases lower levels of most toxic chemicals and harmful substances compared to conventional cigarettes. However, toxic compounds are not completely removed from the HTP aerosol. Moreover, some independent studies have suggested that pyrolysis processes can still be present during HTP use. On the one hand, the levels of some toxicants can be reduced during HTP use but, on the other hand, HTP users can be exposed to higher levels of other toxic chemical and harmful substances compared to tobacco smoke.

\section{Evidence from the experimental animal and cellular studies}

The tobacco industry has performed multiple [22,37-70] in vitro studies on human bronchial epithelial cells, coronary arterial endothelial cells, a 3-D nasal culture model, gingival epithelial organotypic cultures, monocytic cells, and in vivo mouse models (Table 2). The results of these studies have indicated that the aerosol from HTPs has lower toxicity and no new hazards compared to cigarette smoke [10,11,22,39-68].

The aqueous aerosol extract from IQOS has reduced effects on the adhesion of monocytic cells to human coronary endothelial cells compared to the aqueous reference cigarette smoke extract [55]. The aerosol extracts from IQOS were also found to induce less inflammation and migration, and to be less cytotoxic than those from burning conventional cigarettes [56]. The IQOS aerosol exerted a weaker biological impact on human organotypic bronchial epithelial cells than cigarette smoke at similar nicotine concentrations [57]. Compared to cigarette smoke, there was a substantially lower impact of the IQOS aerosol in terms of alterations in tissue morphology, secretion of pro-inflammatory mediators, impaired ciliary function, increased perturbed transcriptomes, and miRNA expression profiles [58]. Exposure to IQOS aerosols had a lower impact on the pathophysiology of human gingival organotypic cultures than conventional cigarette smoke [59]. Cigarette smoke caused significant discoloration of dental composite resins [60] while this effect was minimized during IQOS use [60]. 


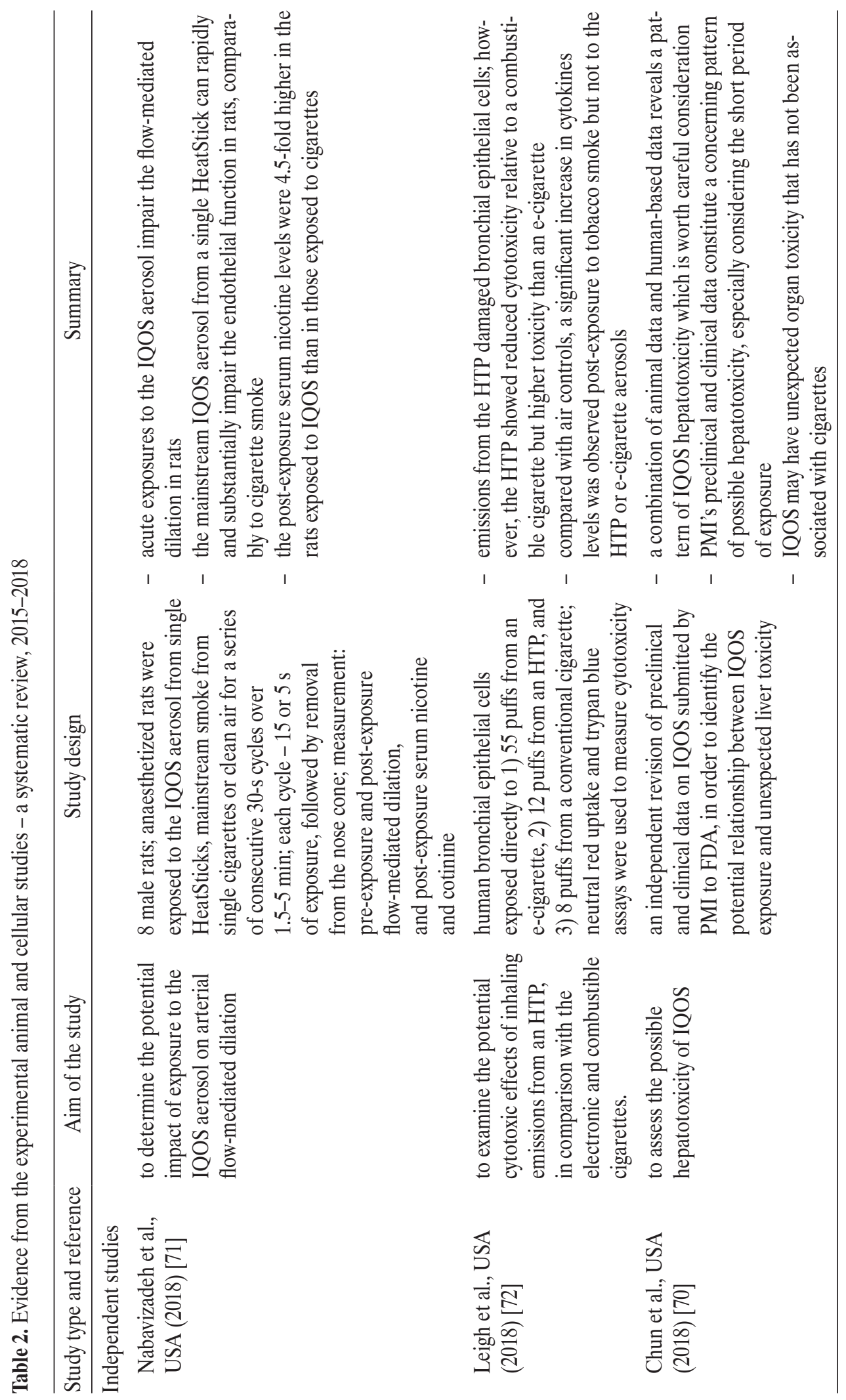




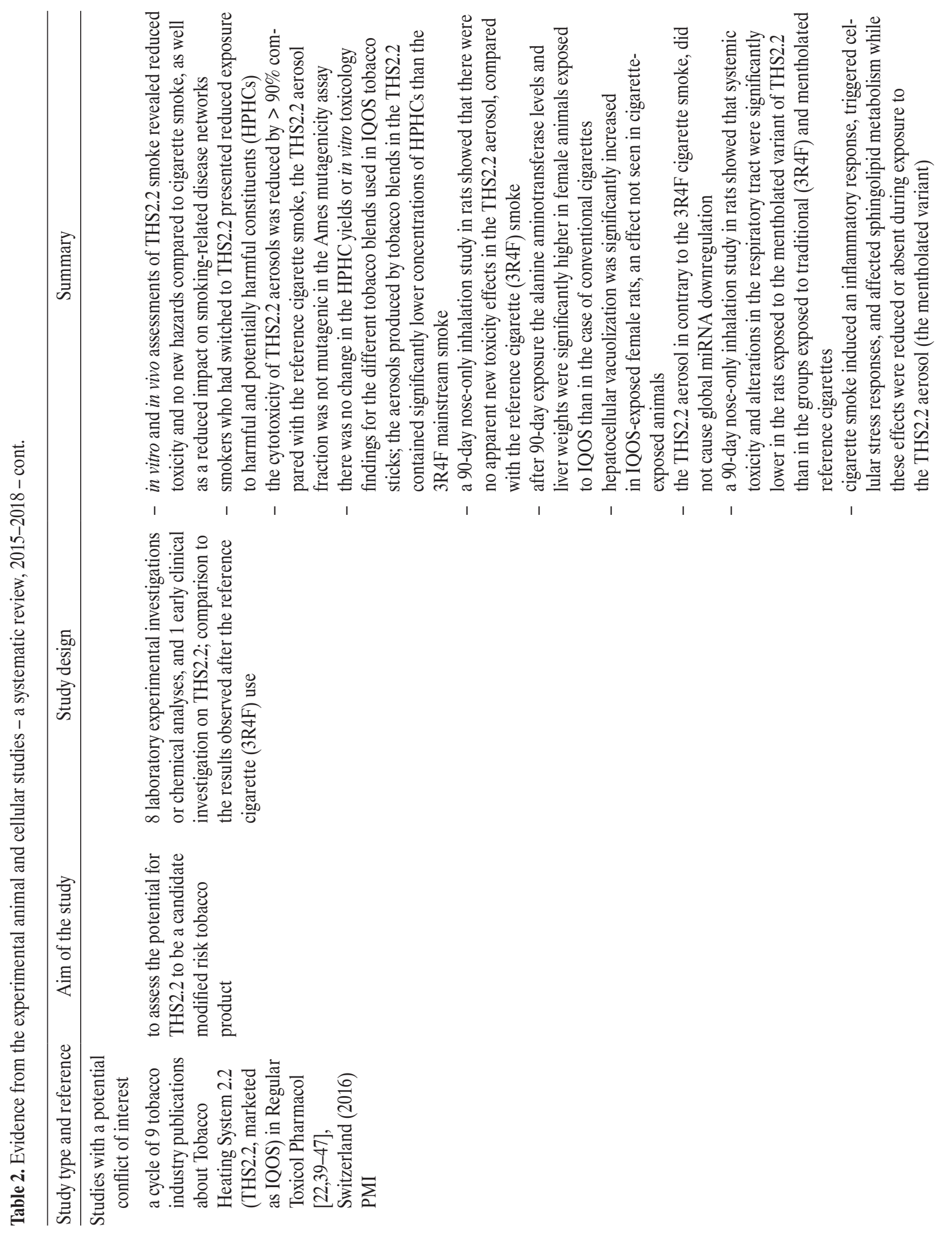



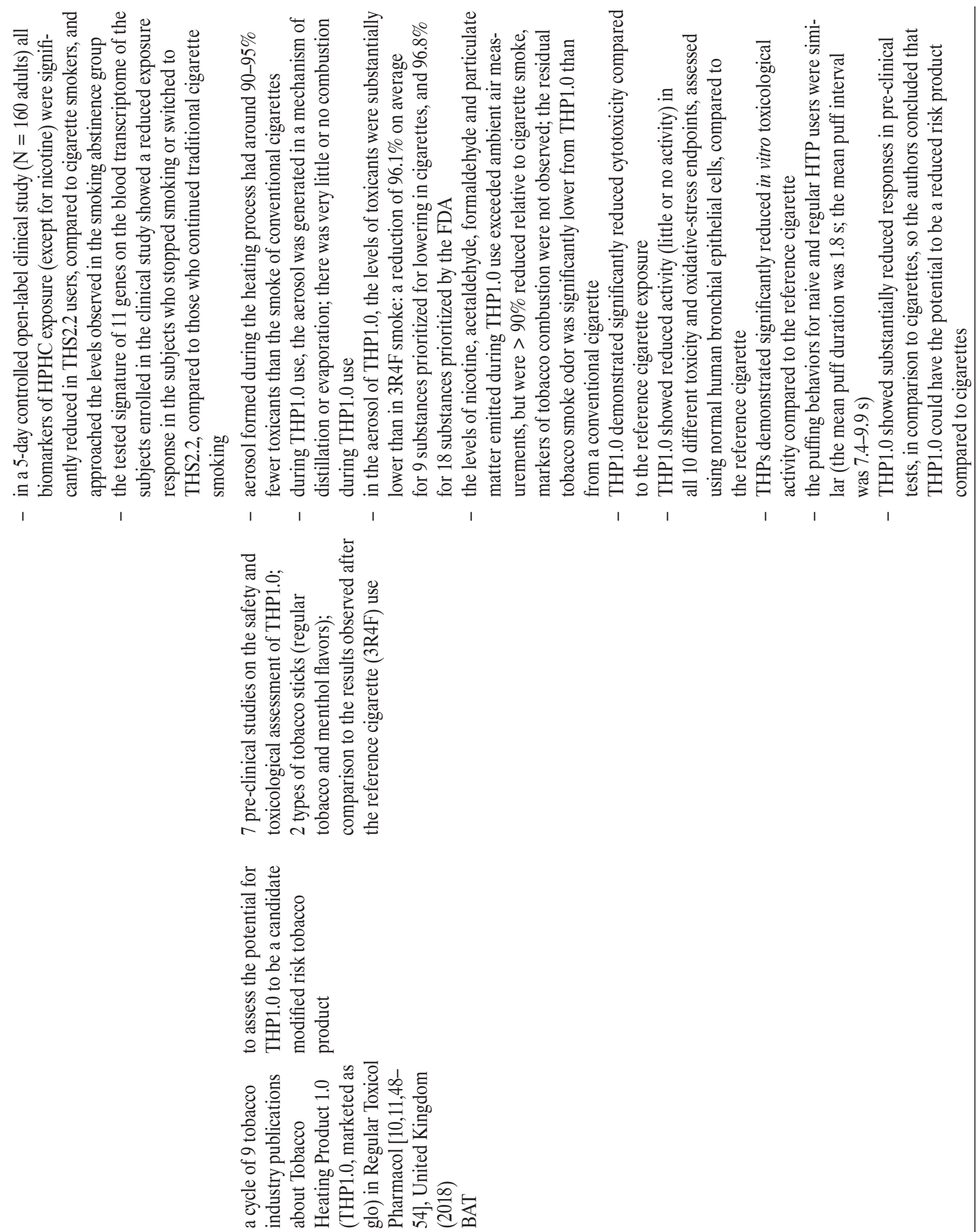


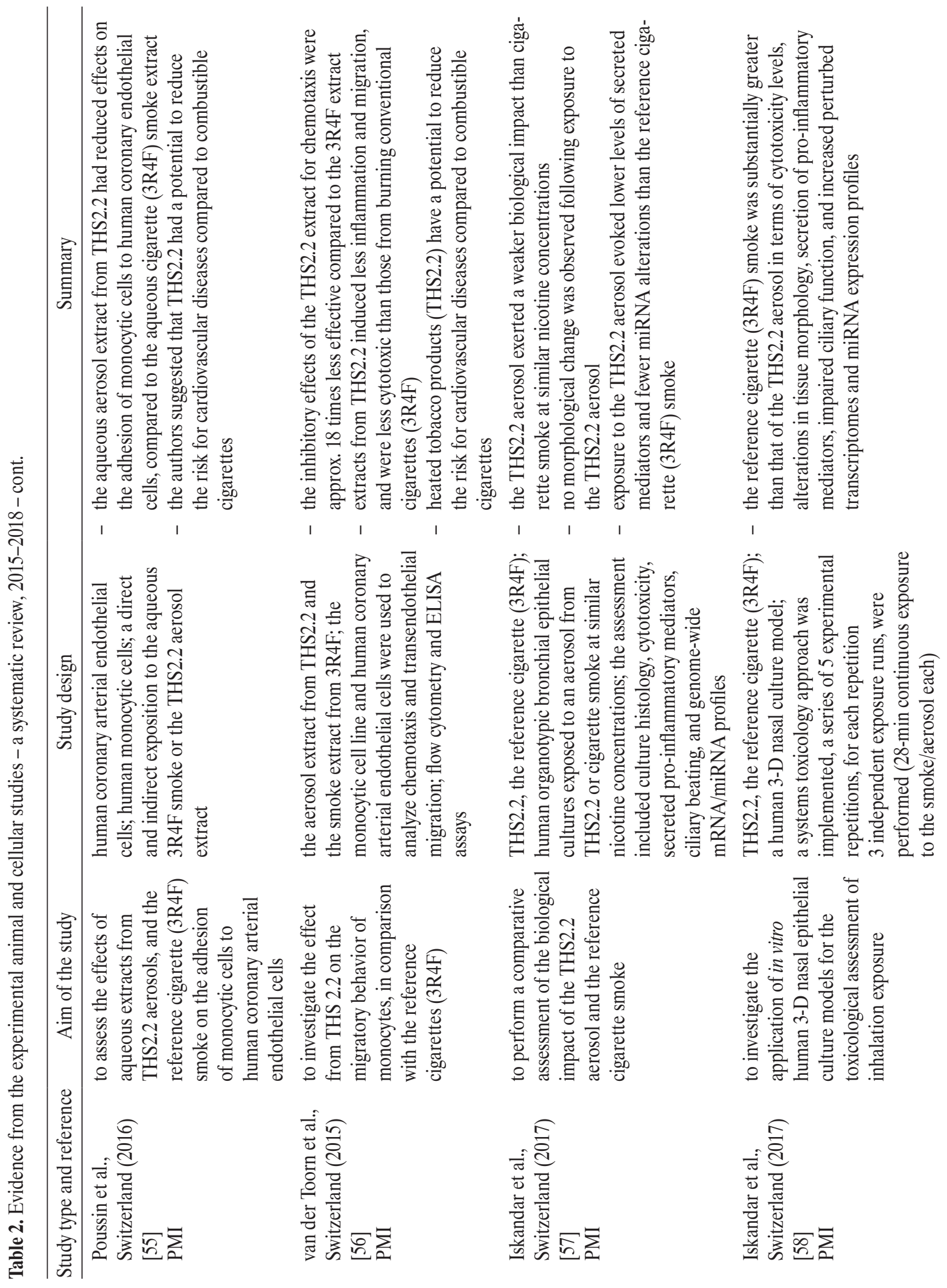



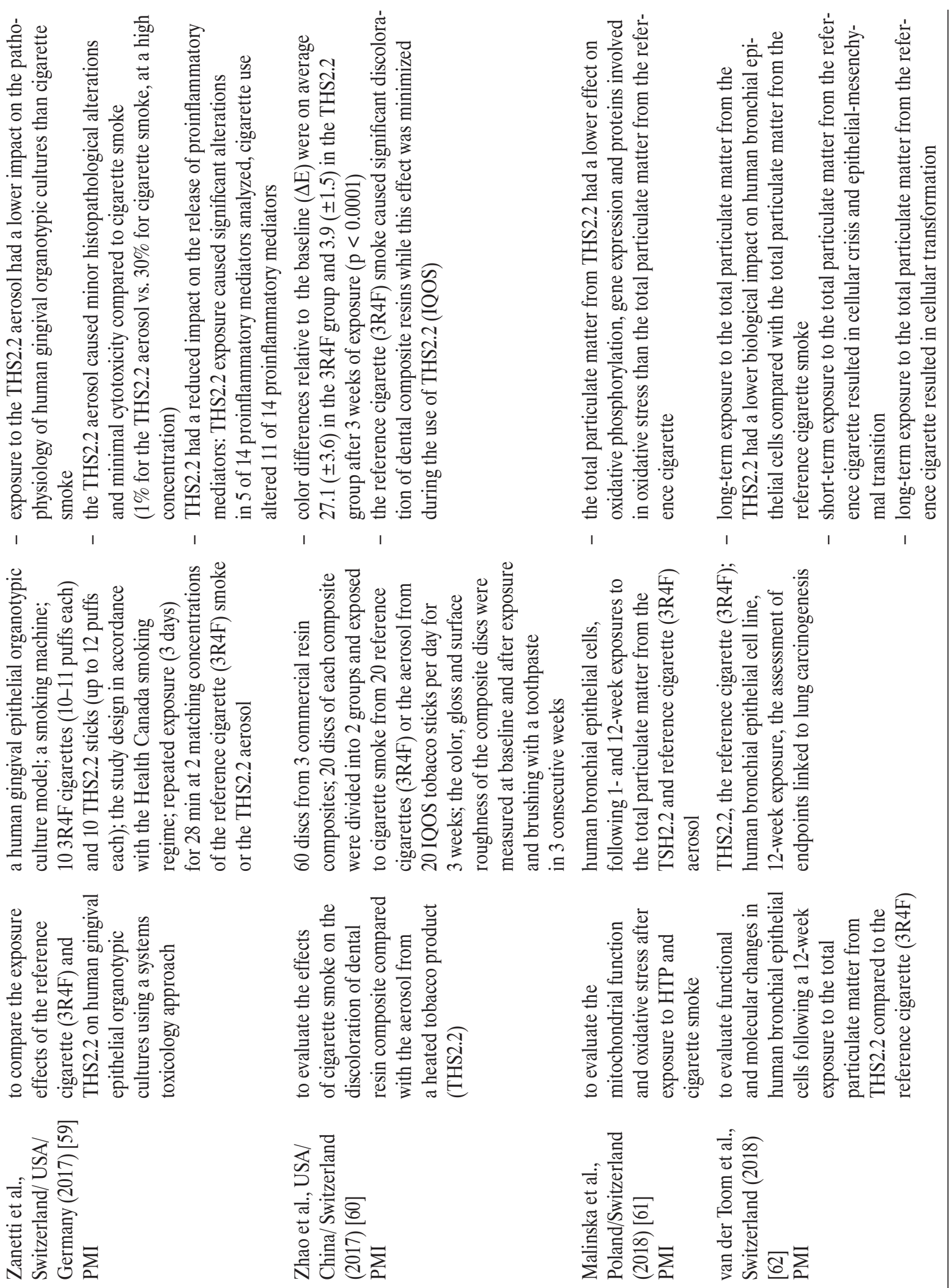


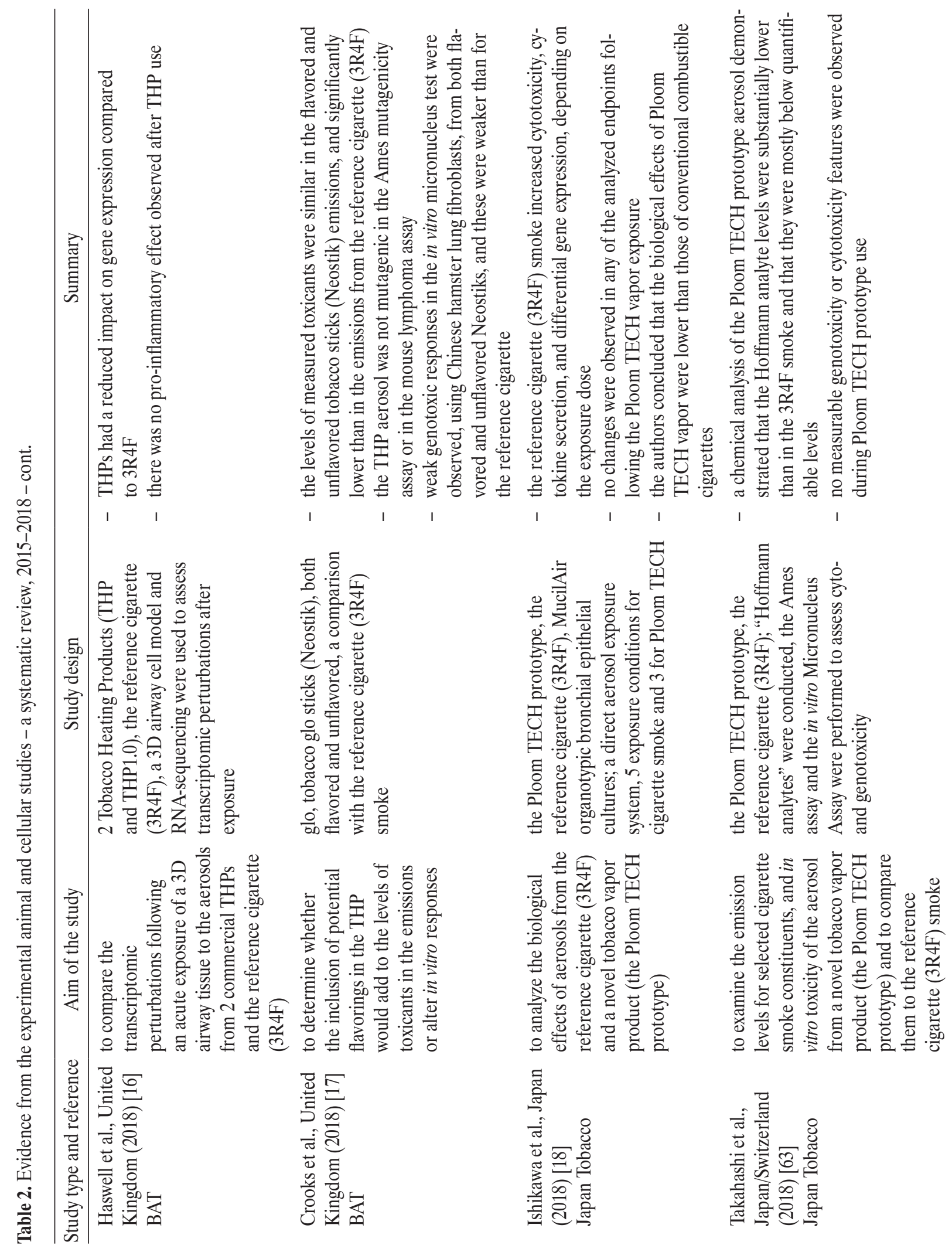




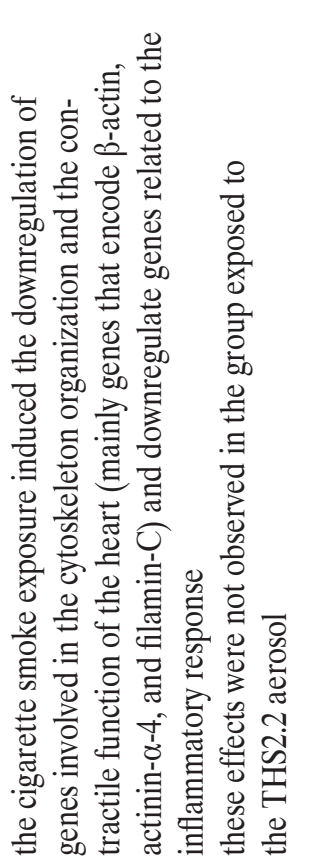

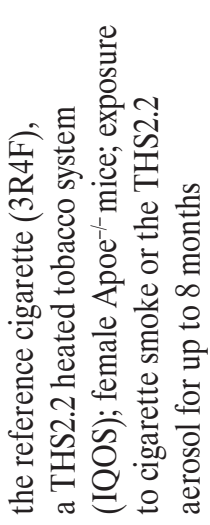

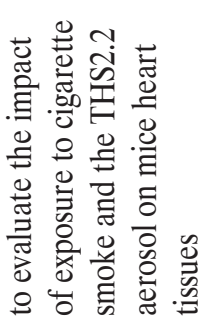

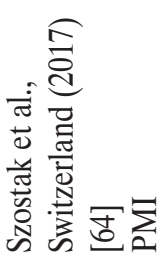

च्ष

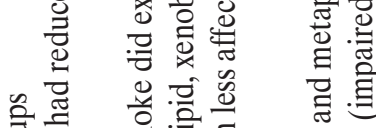

$\frac{5}{2}$

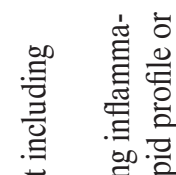

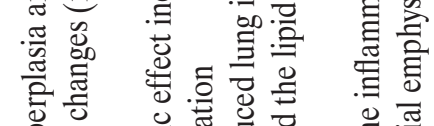

on

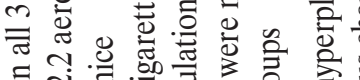

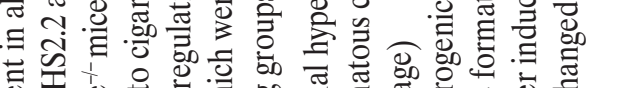

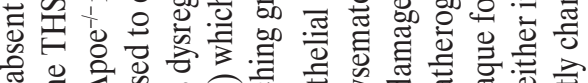

๘

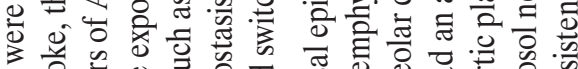

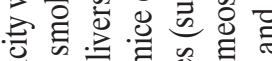

额 o

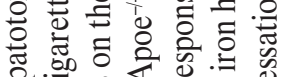

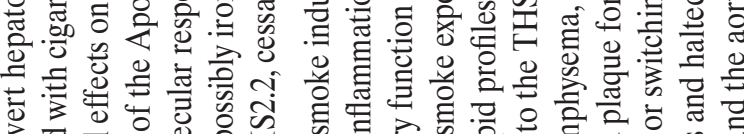

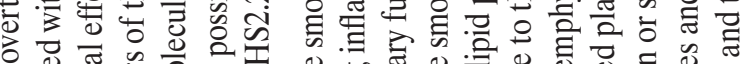

焉要

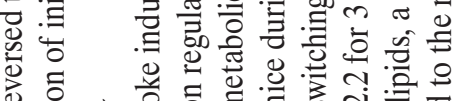

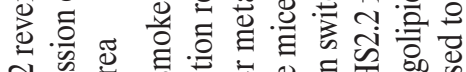

กิ

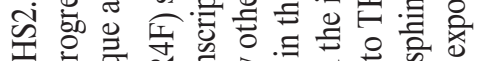

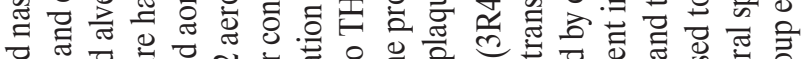

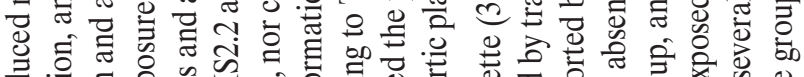

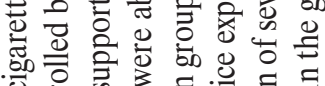

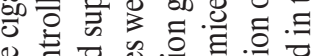

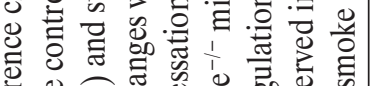

空

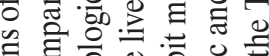

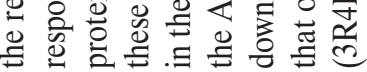

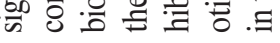

1
1

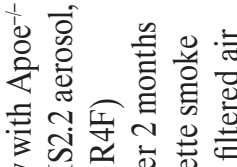

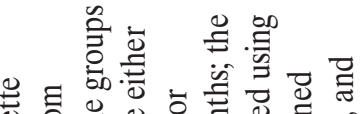

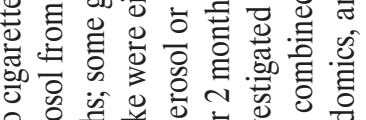

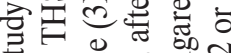

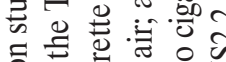

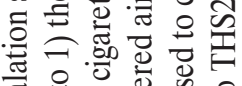

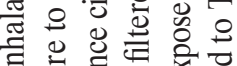

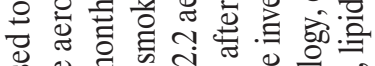

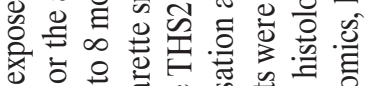

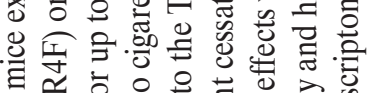

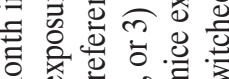

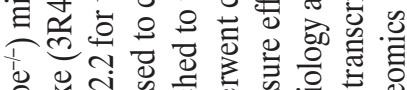

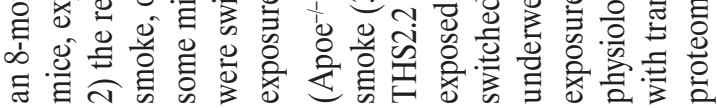

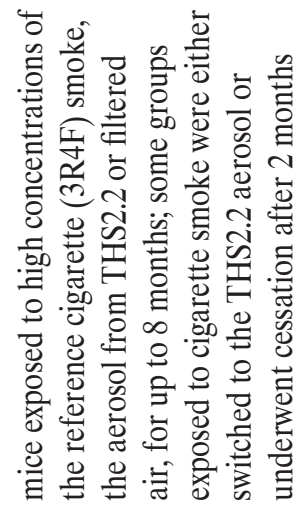

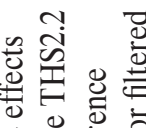

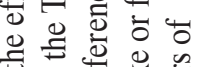

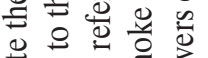

.

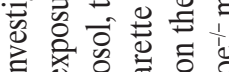

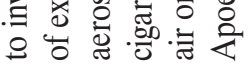

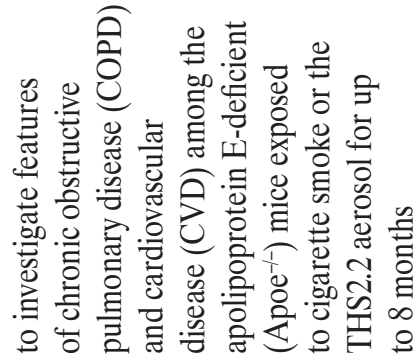

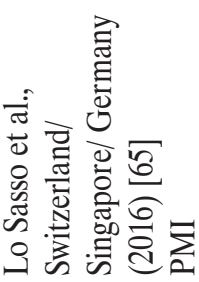

政踥

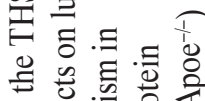

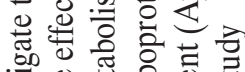

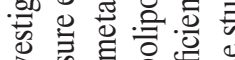

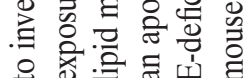

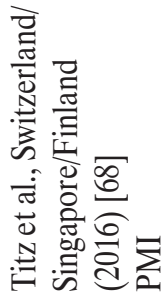

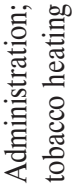

觜

골

.

要

范

定

惫

䓂

要

注

를

可

焉

들

放

I寻

芯焉

을

造苍

츤

ฮู 8

选 :

됴 언

氙 的

1 少

完荡

iิ 苍气

苍

을

节

证

氖.

牛 클

들 츨

흥 矛

응

을 그

I 至

苛总

记 
The total particulate matter from IQOS had a lower effect on oxidative phosphorylation, gene expression, and proteins involved in oxidative stress, compared to the total particulate matter from the reference cigarette [61]. Longterm exposure to the total particulate matter from IQOS had a lower biological impact on the human bronchial epithelial cells line compared to the total particulate matter from cigarette smoke [62].

The aerosol from glo also demonstrated significantly reduced in vitro toxicological activity compared to conventional cigarettes $[16,17]$. There was no pro-inflammatory effect observed after the use of glo [16]. The glo aerosol was not mutagenic in the Ames mutagenicity assay or in the mouse lymphoma [17]. Similarly, no measurable genotoxicity or cytotoxicity features were observed after Ploom TECH use [63], and the biological effects of the Ploom TECH aerosol were also lower than those of conventional cigarette smoke [18].

Most in vivo studies were performed on apolipoprotein E-deficient $\left(\mathrm{Apoe}^{--}\right)$mouse models exposed to cigarette smoke or the IQOS aerosol for 8 months (Table 2). In contrast to traditional cigarette smoke, IQOS aerosols did not affect the downregulation of genes involved in the cytoskeleton organization, contractile function of the heart, or genes related to the inflammatory responses [64]. The IQOS aerosol had reduced biological effects on the livers of the Apoe ${ }^{-/}$mice [65]. However, Wong et al. observed a significant increase in alanine aminotransferase (ALT), liver weights, and hepatocellular vacuolization in female rats exposed to IQOS. These effects were lower or absent in the case of cigarette-exposed rats [42]. Exposure to the IQOS aerosol did not induce lung inflammation or emphysema, nor did it consistently change the lipid profile or enhance the aortic plaque formation [66,67]. There was no relevant IQOS aerosol exposure effect on lung lipid metabolism either [68].

All the studies presented above were performed or sponsored by the tobacco industry. Moreover, most of them were published in 1 journal that had a history of concealed pro-industry bias [69].

An independent review of industry sponsored preclinical and clinical data on IQOS, performed by Chun et al., points to the potential hepatotoxic effects of IQOS use [70]. A combination of animal data and human-based data reveals a concerning pattern of possible hepatotoxicity, especially considering the short period of exposure. Chun et al. suggested that IQOS might have unexpected organ toxicity, not observed during cigarette smoking. Independent experimental animal and cellular studies on HTPs are very limited. Nabavizadeh et al. showed that the mainstream IQOS aerosol from a single tobacco stick might rapidly and substantially impair the endothelial function in rats, comparable to smoke from a cigarette. The use of IQOS does not necessarily avoid the adverse cardiovascular effects of cigarette smoking [71]. Leigh et al. reported that the aerosol emitted from IQOS damaged human bronchial epithelial cells; however, IQOS cytotoxicity was lower compared to that of a combustible cigarette, but it exhibited higher toxicity than an e-cigarette, which was consistent with tobacco industry data [72].

\section{Potential impact of heated tobacco on human health}

Based on studies sponsored by the tobacco industry (Table 3), among healthy Japanese adult smokers, the results have shown that HTPs effectively deliver nicotine and achieve similar pharmacokinetic profiles to combustible cigarettes [12,36,73]. Brossard et al. showed that the nicotine pharmacokinetic profile of IQOS was close to that of conventional cigarettes with similar urge-tosmoke levels [36]. The use of IQOS or glo reduced the exposure to smoke toxicants in a manner comparable to quitting tobacco use [74,75]. After switching from conventional cigarettes to HTPs (IQOS or glo), a significant reduction in the levels of biomarkers of exposure to harmful and potentially harmful constituents was observed [76-78]. 


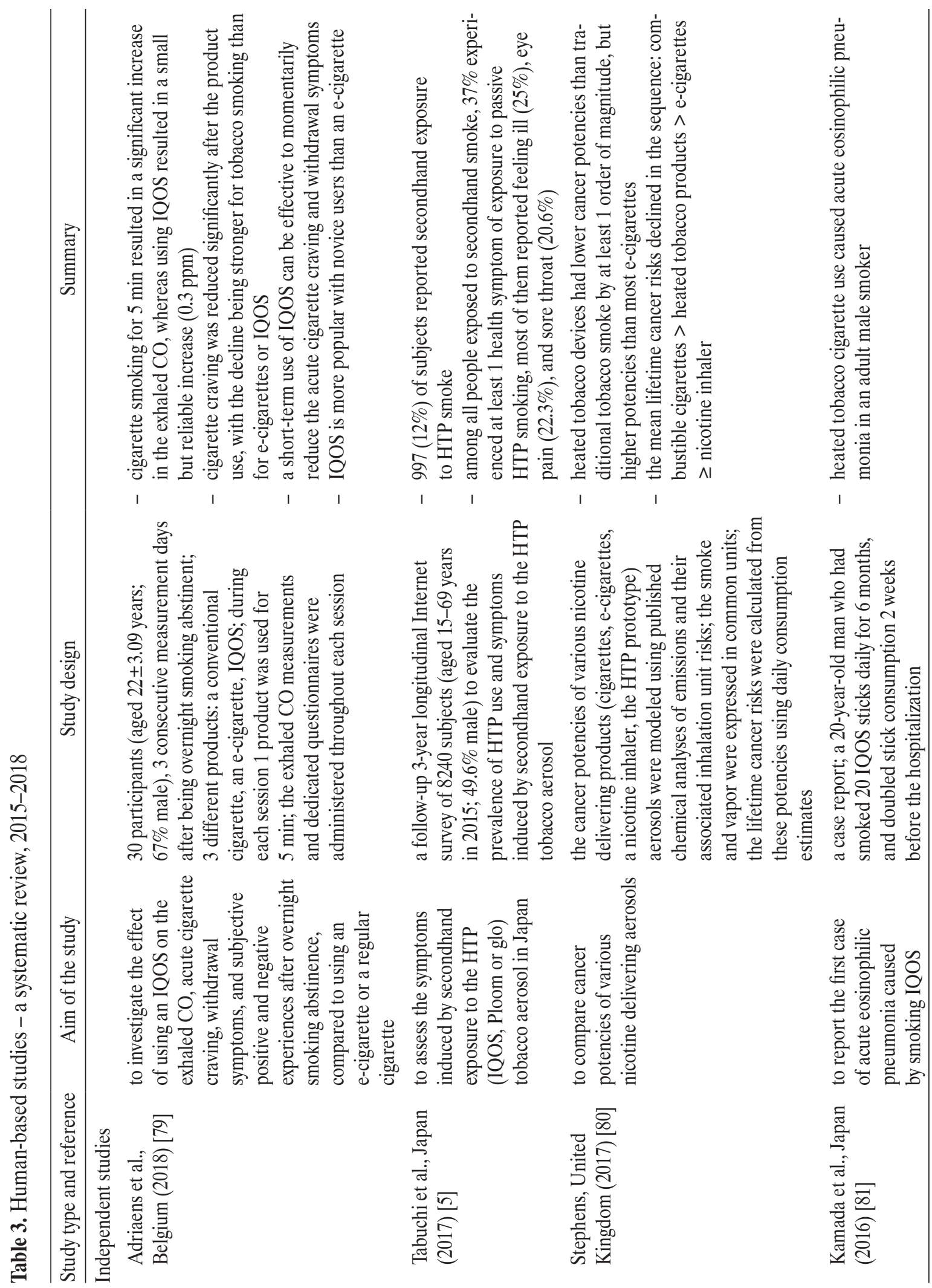



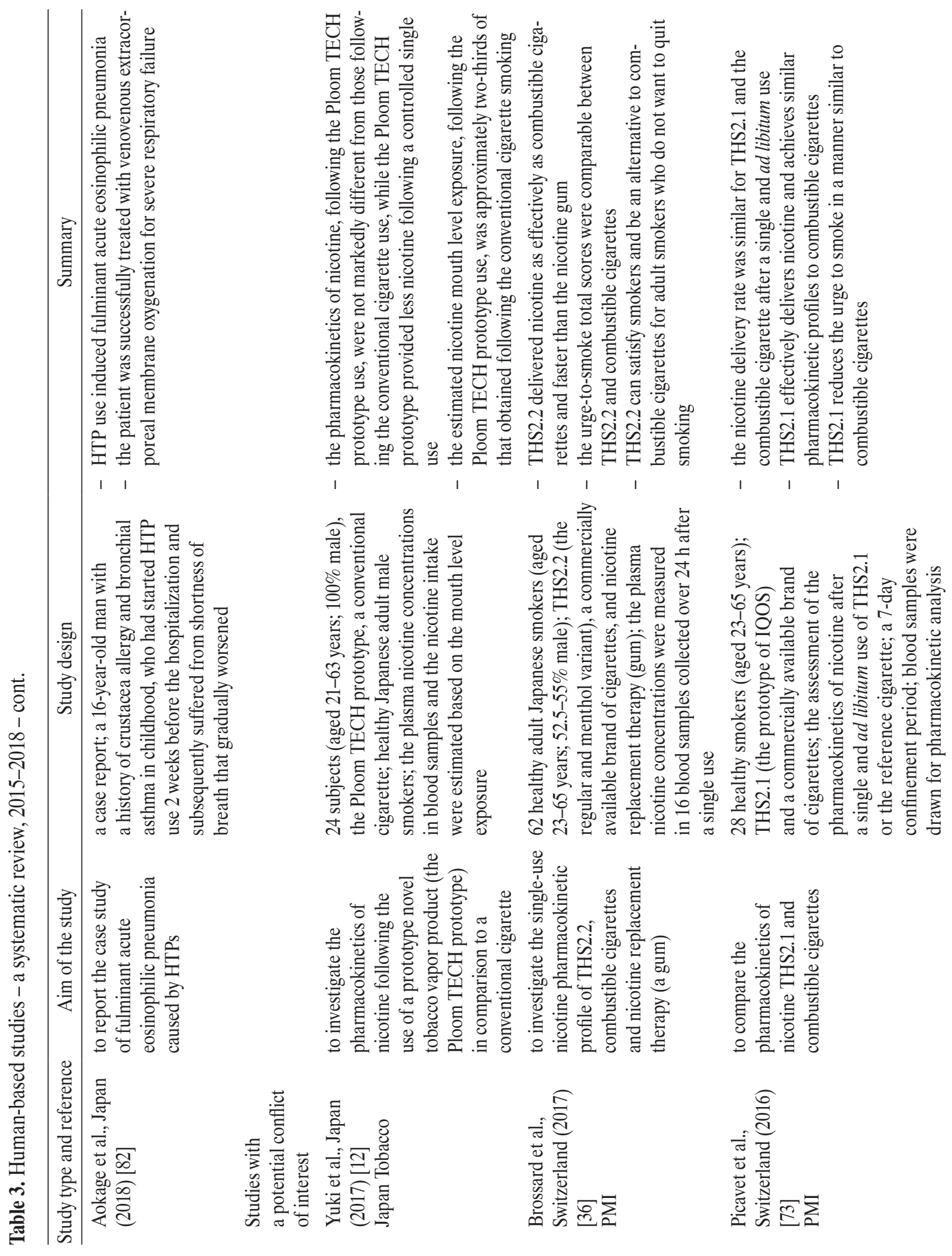

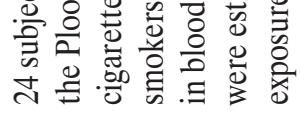

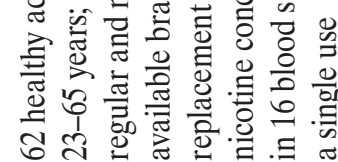

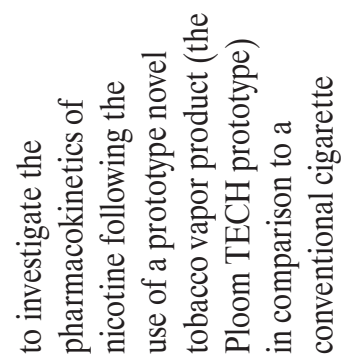
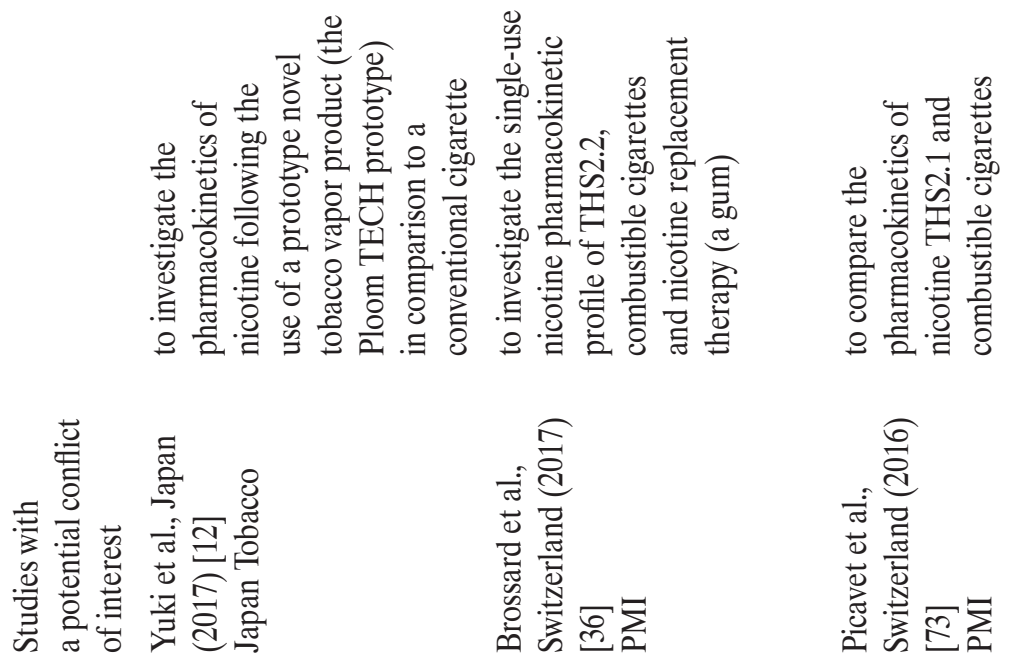

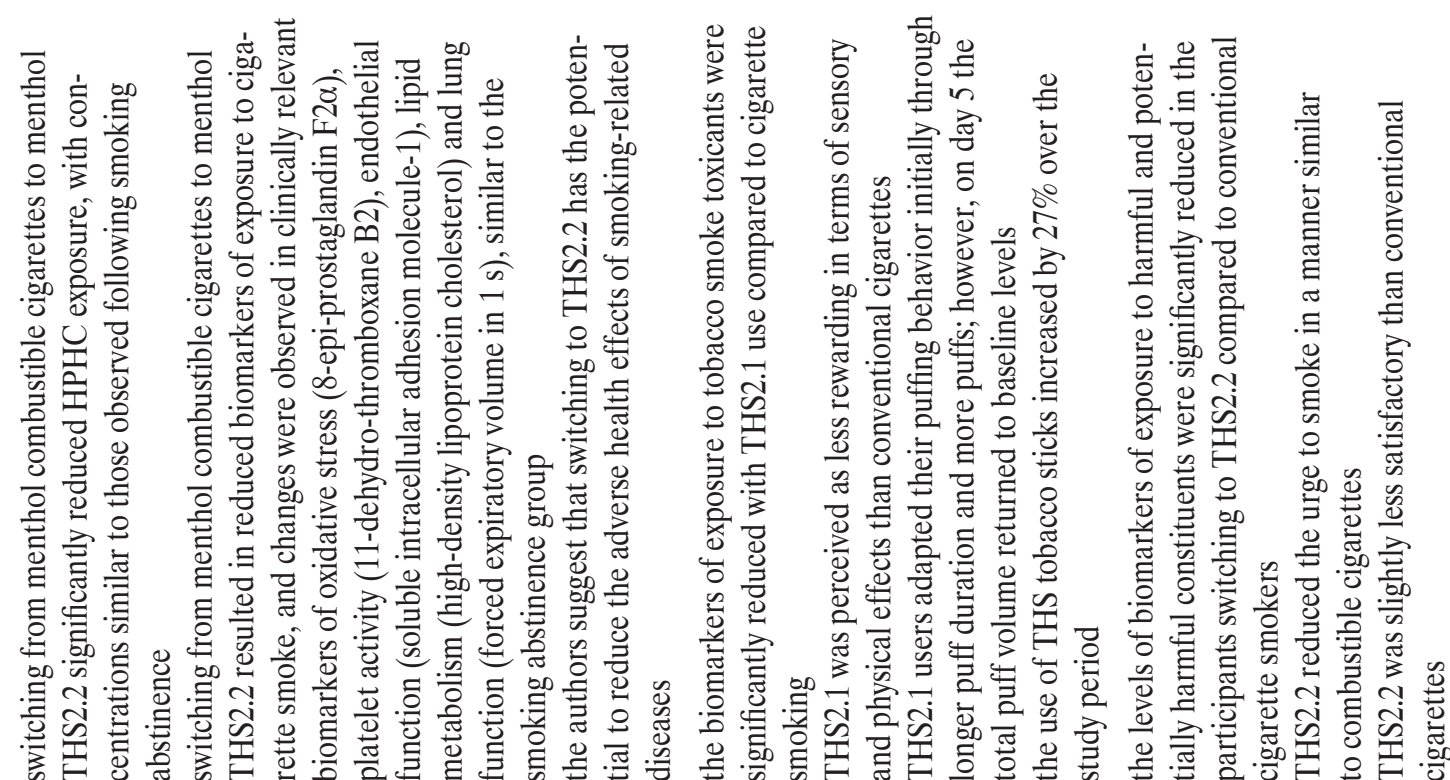

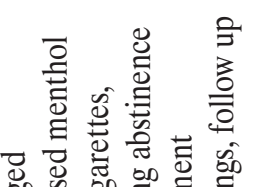

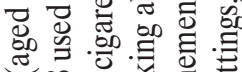

s

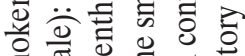

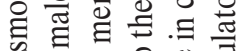

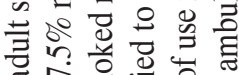

证步

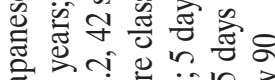

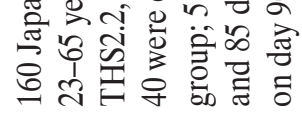
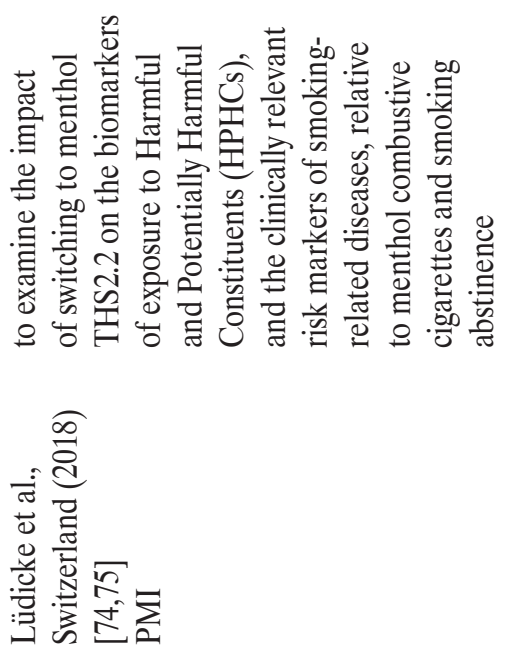

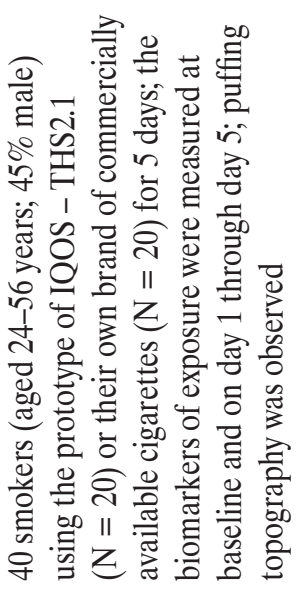

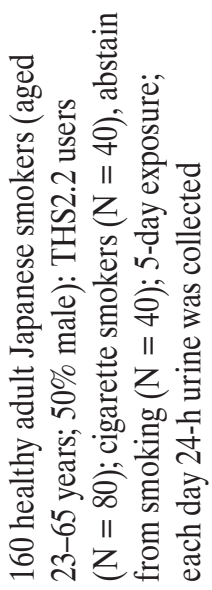
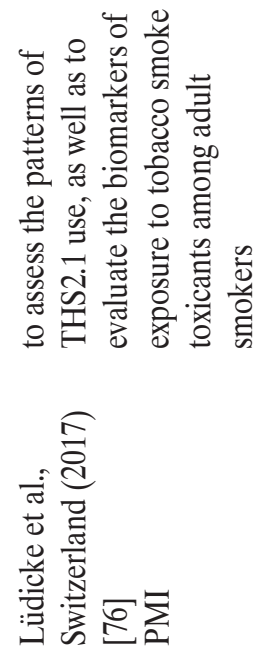
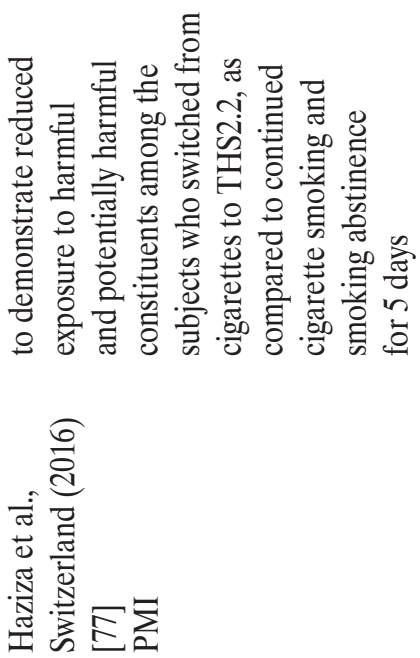


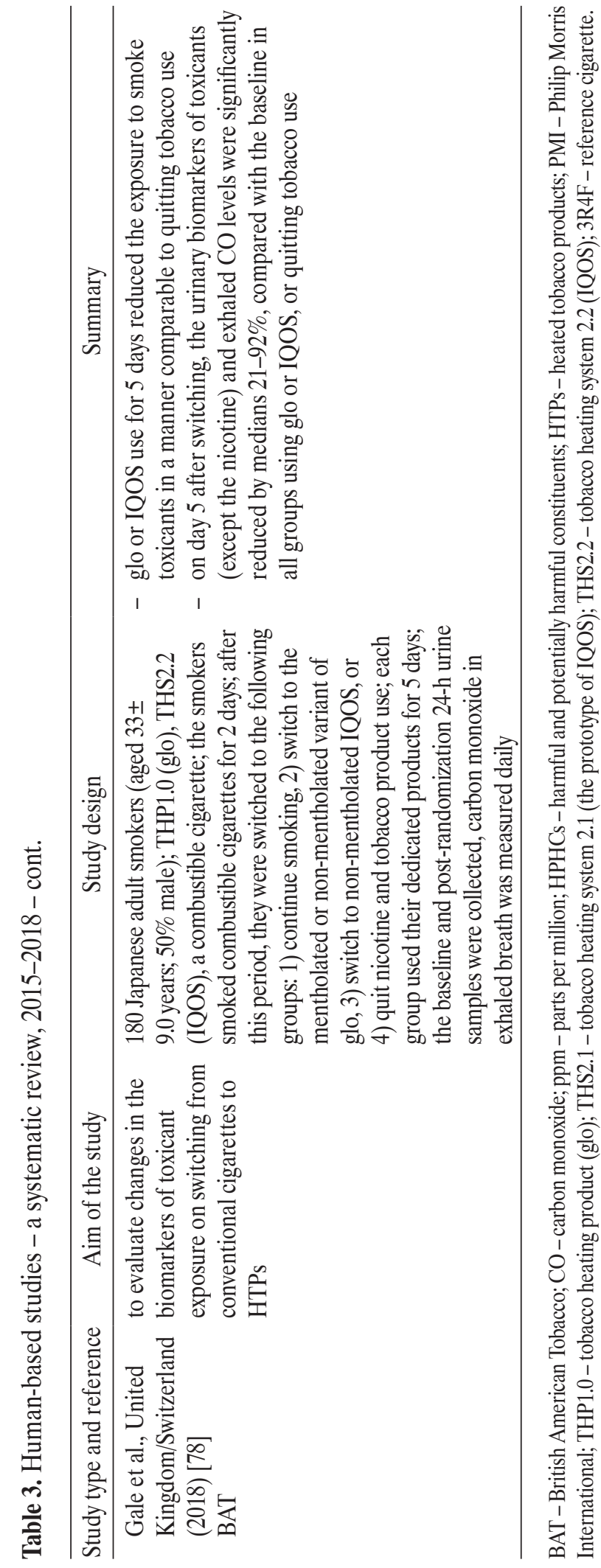

Independent studies performed with the aim of assessing the health impact of HTP use are very limited (Table 3). Adriaens et al. showed that $5 \mathrm{~min}$ of IQOS use resulted in a small but reliable increase ( $0.3 \mathrm{ppm})$ in the exhaled CO level [79]. Stephens et al. compared cancer potencies of various nicotine delivering aerosols [80]. Performed estimations revealed that HTPs had lower cancer potencies than traditional cigarettes, but higher potencies than most e-cigarettes [80].

Tabuchi et al. showed that among 8240 subjects who participated in a 3-year longitudinal survey, $12 \%(\mathrm{~N}=997)$ reported secondhand exposure to heated tobacco aerosols [6]. Among all people exposed to secondhand smoke, $37 \%$ had experienced at least 1 health symptom. The most common reported symptoms after secondhand exposure to IQOS smoke were: feeling ill (25\%), eye pain $(22.3 \%)$ and sore throat (20.6\%) [6]. The highest prevalence of symptoms caused by secondhand exposure to HTP smoke was observed among never-users of any tobacco products [6]. Researchers from Japan reported 2 cases of acute eosinophilic pneumonia following HTP use [81,82]. The first case of acute eosinophilic pneumonia was diagnosed in a 20 -yearold man who had smoked 20 IQOS sticks daily for 6 months and doubled stick consumption 2 weeks before the hospitalization [81]. The second case of fulminant acute eosinophilic pneumonia was diagnosed in 16-year-old man with bronchial asthma in childhood, who had used HTPs for 2 weeks [82]. There were no available human-based studies assessing the potential impact of HTP use on lung physiology.

Moazed et al. reviewed the PMI modified risk tobacco product (MRTP) application to the U.S. Food and Drug Administration in 2016 [83]. An assessment of industry data revealed that IQOS use was associated with significant pulmonary and immunomodulatory toxicities, with no detectable differences between cigarette smokers and those who were switched to IQOS [83]. Furthermore, the analysis of the same PMI MTRP application by Glantz [84] suggested that, in human testing, IQOS did not reveal detectably better measures of the biomarkers of potential 
harm than traditional cigarettes. Glantz pointed out that there were no statistically significant differences in the biomarkers of potential harm between IQOS and conventional cigarette users among American adults (for 23 of the 24 biomarkers) and Japanese adults (for 10 of the 13 biomarkers) [84].

Although tobacco industry sponsored studies have mostly shown health benefits of switching from conventional cigarette use to HTP use, independent studies indicate some potentially harmful consequences of exposure to HTP aerosols. Currently there is no evidence regarding the long-term health effects of HTP use. The potential role of HTPs as a tool in smoking cessation is also unknown.

\section{The frequency of using heated tobacco products}

Heated tobacco products have been widely available for only a few years. The data on the frequency of use of these products are mainly from Japan and Italy, the test markets where these products were first introduced (Table 4). Tabuchi et al. reported that the number of current IQOS users in Japan was consistently increasing, from $0.3 \%$ in 2015 to $0.6 \%$ in 2016, and up to $3.6 \%$ in 2017 [5,6]. The prevalence of Ploom TECH use in 2015-2017 increased 4-fold (from $0.3 \%$ to $1.2 \%$ ) [5,6]. Among 8240 surveyed subjects, $0.8 \%$ declared the current use of glo [5,6]. Face-to-face interviews with 3086 Italians aged $\geq 15$ years showed that $19.5 \%$ of respondents were aware of heated tobacco products [2,3]. Ever use of HTPs was reported by $1.4 \%$ of subjects and $2.3 \%$ of subjects intended to try HTPs in the near future.

Brose et al. estimated the awareness and prevalence of HTP use in Great Britain [85]. Among 12696 adult participants, $9.3 \%$ were aware of heated tobacco products. Ever use of HTPs was declared by $1.7 \%$ of respondents and $0.8 \%$ were current users [85]. Kim et al. reported that among 228 young Korean adults, more than one-third (38.1\%) were aware of IQOS [86]. The current IQOS use was declared by $3.5 \%$ of respondents, wherein all current
IQOS users were triple users of conventional cigarettes and e-cigarettes, as well as HTPs [86]. HTPs have also gained popularity in the USA $[87,88]$. From 2016 to 2017, the awareness of HTPs among U.S. adults increased from $9.3 \%$ to $12.4 \%$, ever use increased from $1.4 \%$ to $2.2 \%$, and the current use doubled, from $0.5 \%$ to $1.1 \%$, among U.S. adults [87]. In the USA, the highest awareness of HTPs was observed among current smokers as well as younger adults, under the age of 30 [88].

Tabuchi et al. pointed to the power of mass media and TV broadcasting as a tool to promote the use of IQOS [6]. The highest prevalence of ever IQOS use was observed among people who had seen a TV program where Japanese comedians discussed their IQOS use, compared to those who had not seen it. The willingness to use IQOS was significantly higher among current tobacco smokers with the intention to quit than among those with no intention to quit [6]. Experience with electronic cigarette use indicates that most smokers who reach for an e-cigarette to quit traditional cigarettes are dual users who ultimately use both forms of cigarettes [89]. A risk of dual use exists also in the case of heated tobacco products. Miyazaki et al. indicated a higher tendency (but not statistically significant) to ever use heated tobacco products among former smokers with lower education levels [89].

The study from Italy by Liu et al. also revealed that the highest prevalence of ever HTP users was among current e-cigarette users and current cigarette smokers [2,3]. Only $1 \%$ of those who had never smoked cigarettes and $1.2 \%$ of those who were never e-cigarette users had tried IQOS [2]. These findings were supported by a study from Great Britain, conducted by Brose et al [85]. Current e-cigarette users were more likely to use HTPs $(6.2 \%)$ compared to subjects who had never used e-cigarettes $(0.3 \%, \mathrm{p}<0.05)$. Ever e-cigarette users were also more likely to be aware of HTPs [85]. In Korea and the USA, the highest awareness and ever or current use of HTPs were also observed among current smokers or e-cigarette users [86,87]. 


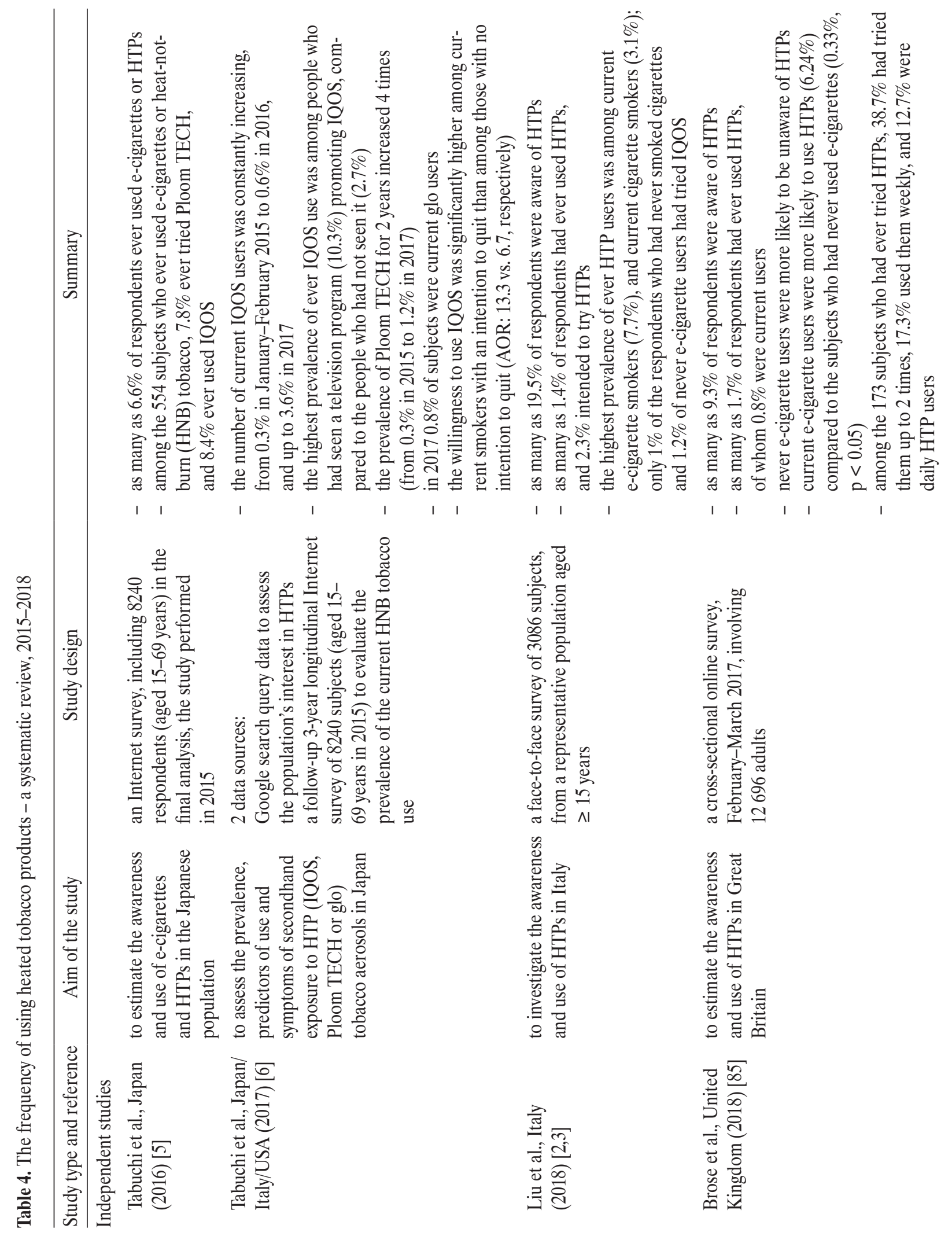




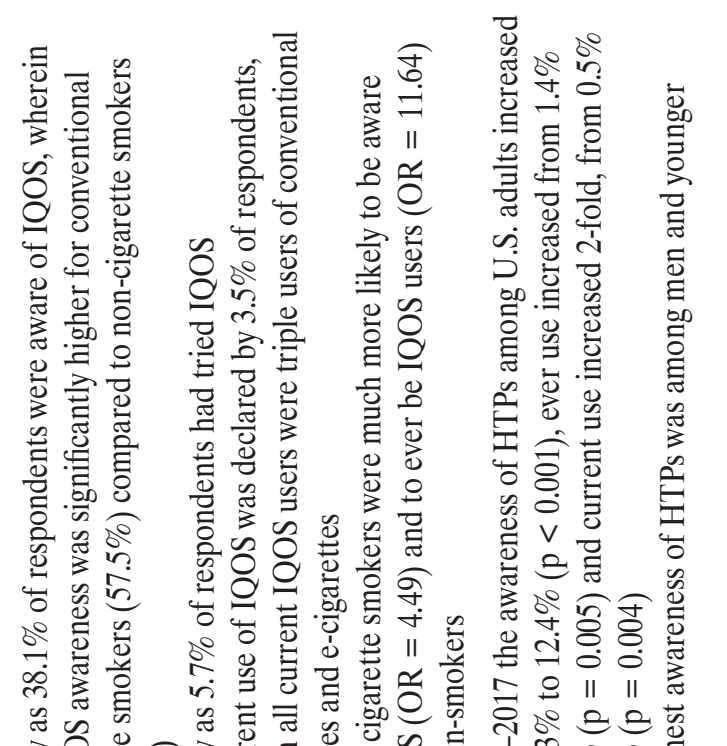

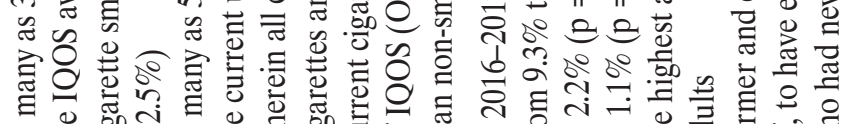

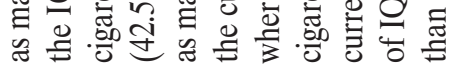

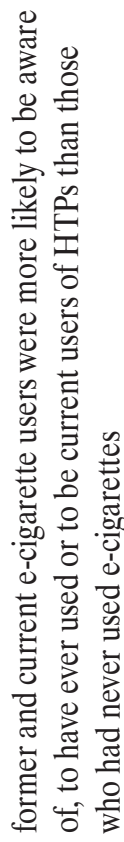

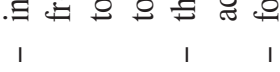
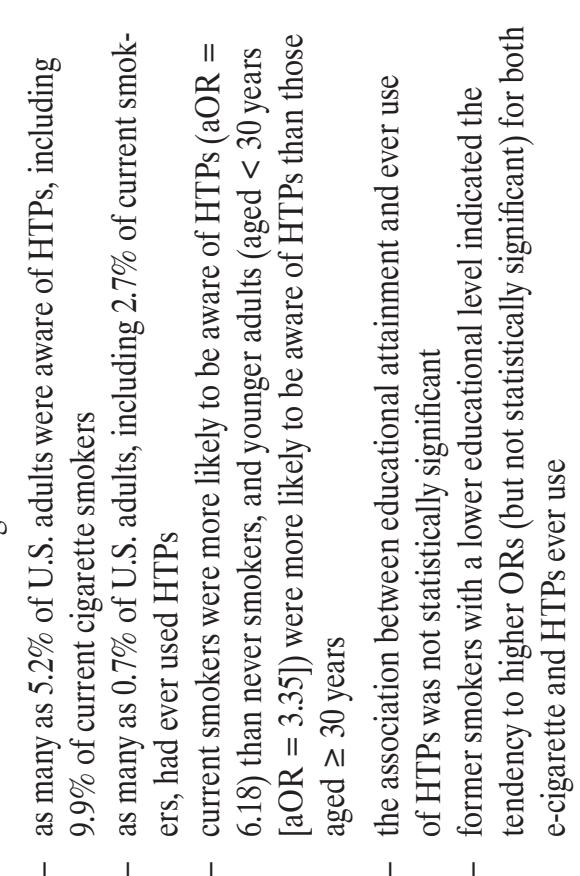

专悹

ํㅗㄹ

$\circlearrowright$

효용

을

政

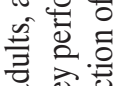

on

홍. 氜

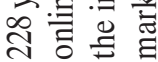

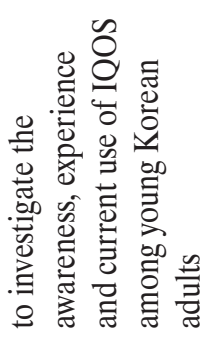

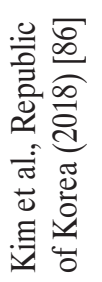

نั่

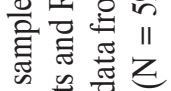

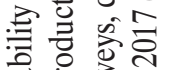

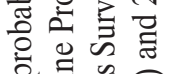

흠

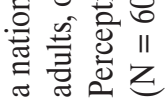

空

$\stackrel{0}{\Xi}$

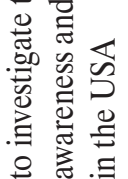

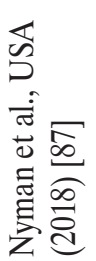

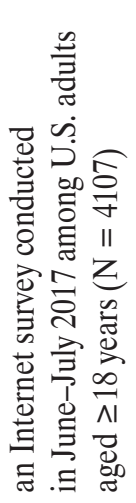

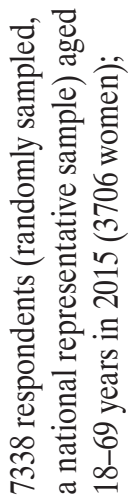
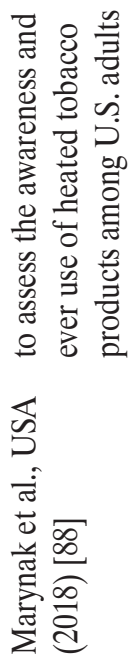

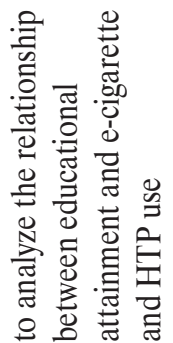

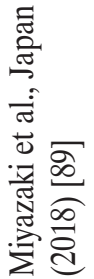




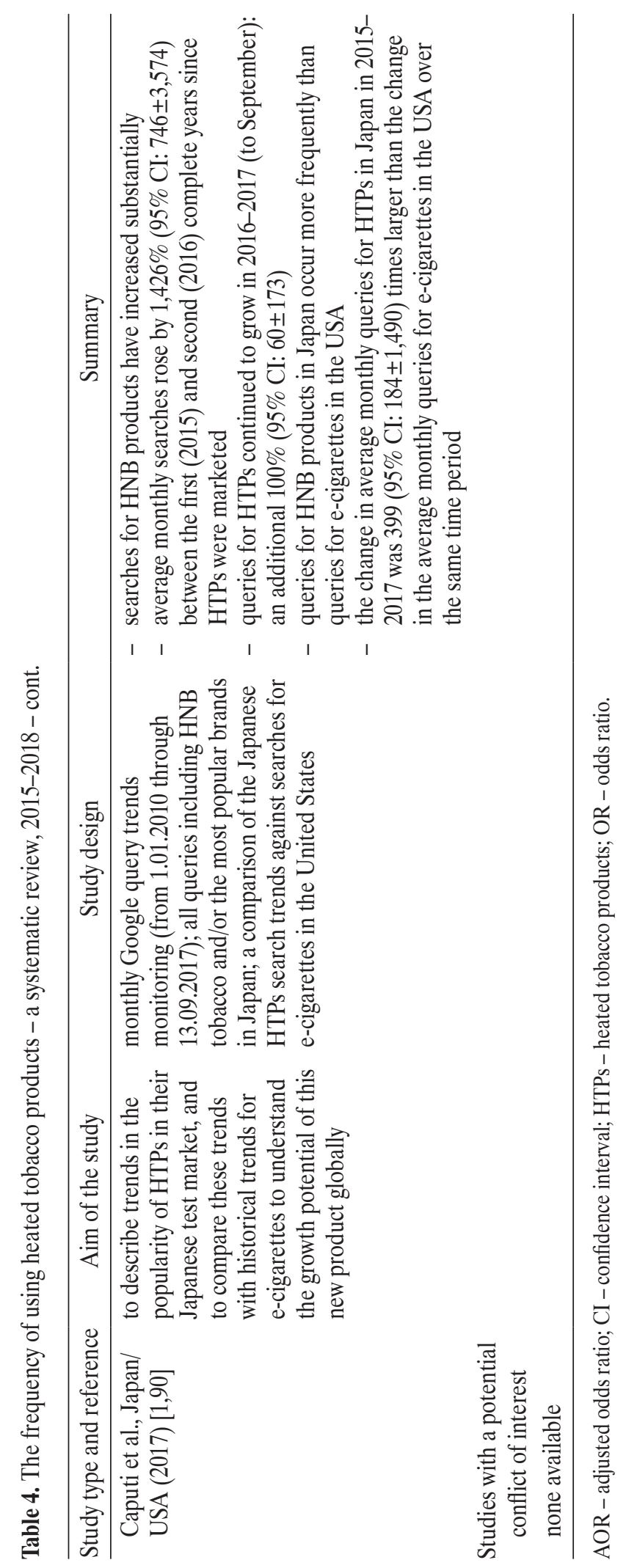

Given the consistent growth and development of the e-cigarette market, it is expected that the popularity of HTPs will also increase rapidly. The 10-fold increase in the frequency of IQOS use in Japan, observed within 3 years, indicates the rapidly growing magnitude of the problem [6]. Caputi et al., assessing the growth potential of heated tobacco products, compared trends in the popularity of HTPs with historical trends for e-cigarette use in Japan $[1,90]$. The monthly Google query trends monitoring revealed that the average monthly searches for HTPs rose by 1,426\% between 2015 and 2016 [90]. Moreover, the change in the average monthly queries for HTPs in Japan in 2015-2017 was approx. 399 times larger than the change in the average monthly queries for e-cigarettes in the USA over the same time period [90].

Due to the increase in the frequency of HTP use and the growing number of countries where these products are being introduced, the prevalence of heated tobacco use requires constant monitoring.

\section{Marketing strategies of HTP promotion}

In many countries, heated tobacco products are under different laws and jurisdiction than conventional cigarettes, which has implications on the marketing strategies and promotion of these products (Table 5). In Japan, heated tobacco products are sold as tobacco products and regulated by the Tobacco Industries Act [5]. In South Korea, heated tobacco products are regulated as a variant of e-cigarettes [4]. In the EU, advertising for IQOS and other heated tobacco devices (except for the tobacco stick) is not regulated under the European Union Tobacco Products Directive (2014/40/EU) [3]. Elias et al. analyzed internal PMI documents [91]. After a comparison of the product design, exposure data, and safety claims, the authors concluded that IQOS appeared to be a variant of Accord without consistent improvements in exposure to aerosol toxic compounds [91]. Elias et al. suggested that the industry's reduced risk claim was an effect of the marketing 


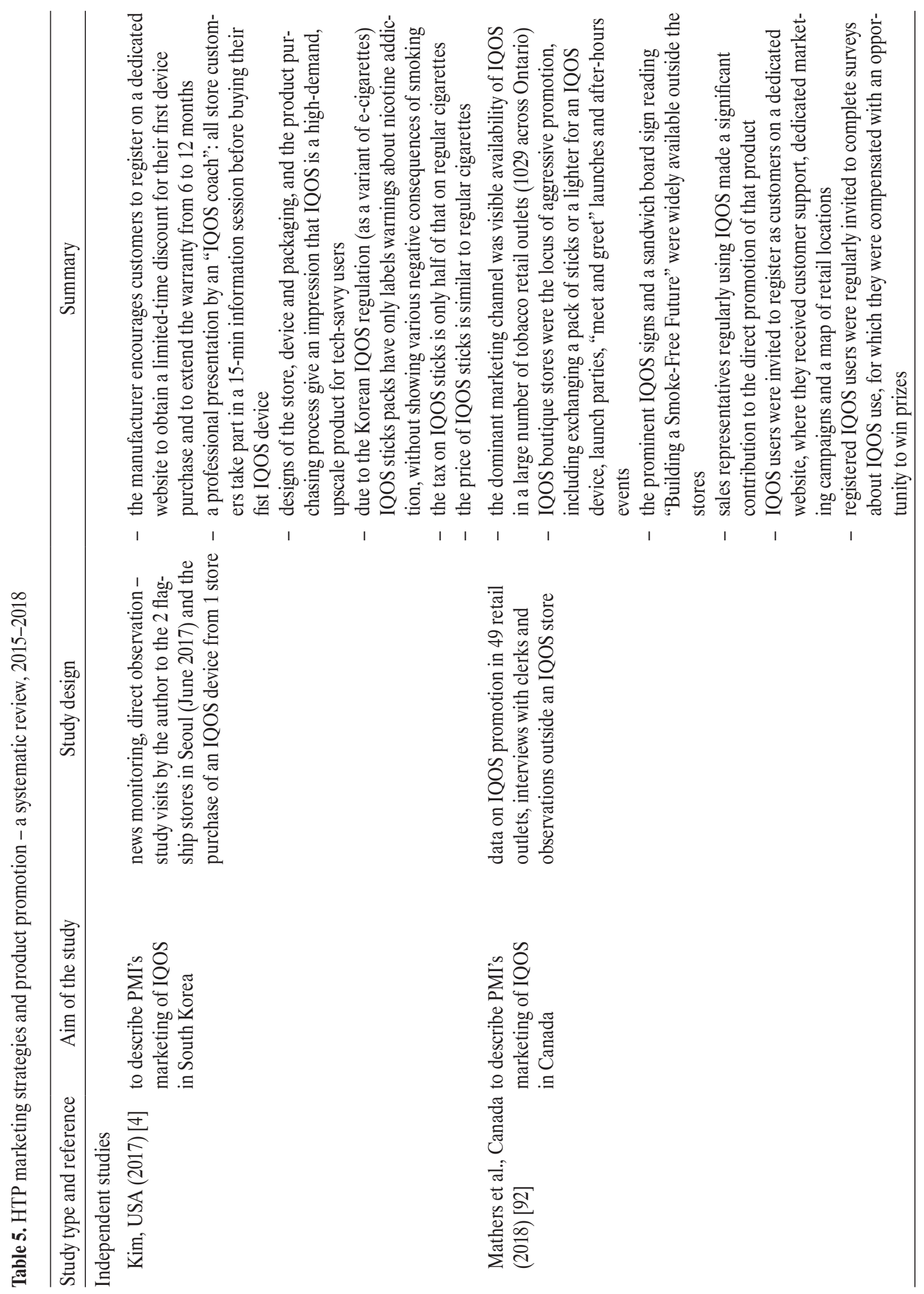




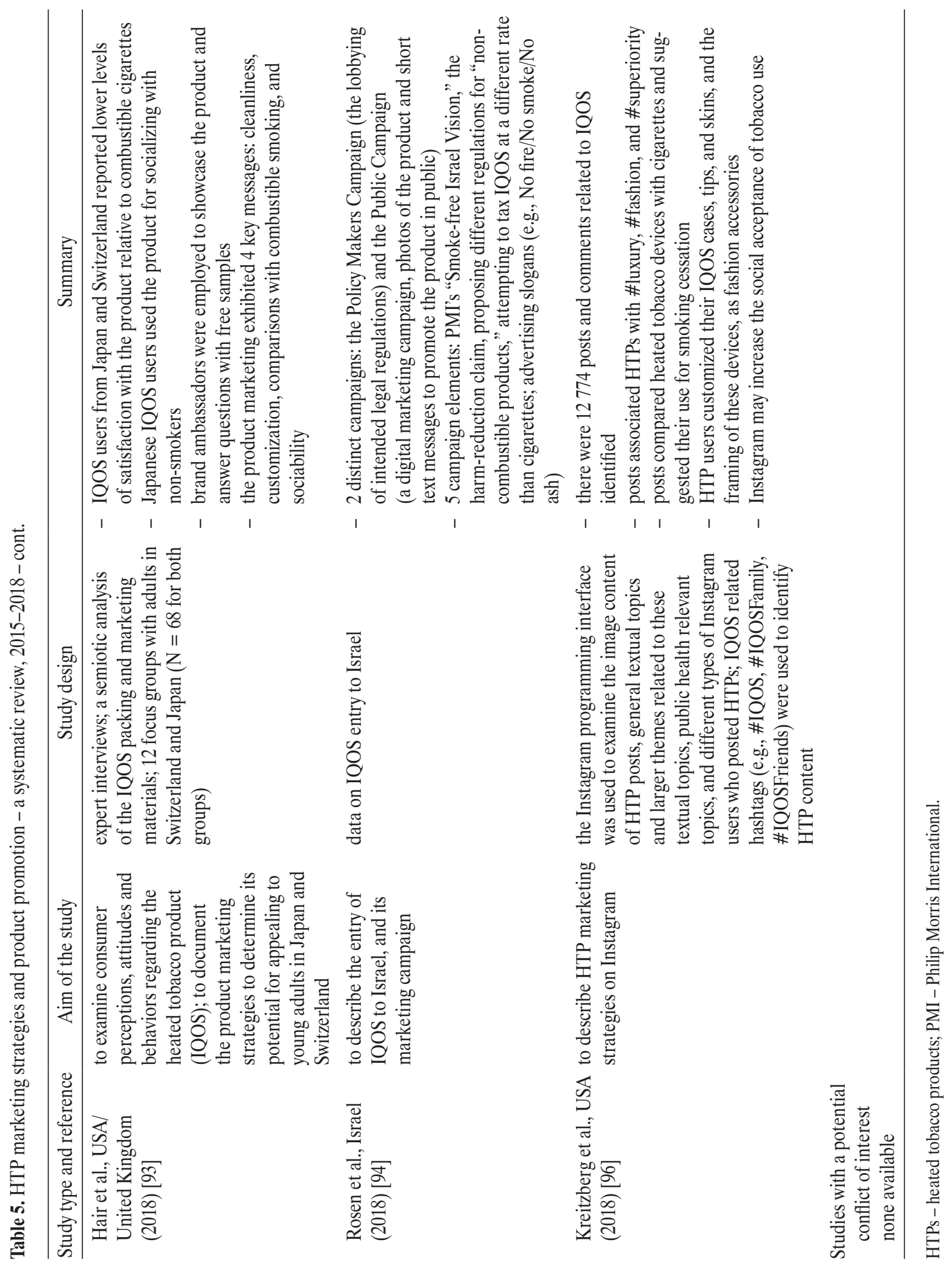


strategy focused on the social and regulatory landscape rather than the result of toxicological differences between IQOS and its precursor, Accord [91].

According to Italian law, advertising and promotions of heated tobacco products are not banned [3]. Dedicated shops called an "IQOS embassy" or an "IQOS boutique" are present in several strategic Italian cites [3]. Similar shops are present in Japan, South Korea, and Canada $[4,92]$. In these fancy concept stores (designed similar to electronics stores), people can try IQOS for free $[3,4]$. Mathers et al. noted that sales representatives in Canada, by regularly using IQOS, made a significant contribution to the direct promotion of this product [92]. A similar marketing strategy was launched in Japan where "brand ambassadors" were employed to showcase the products and answer questions with free samples [93]. In South Korea, each IQOS-store customer takes part in a 15-min professional presentation by an "IQOS coach" before buying their first IQOS device [4]. Rosen et al. identified 5 elements of a marketing campaign of IQOS in Israel, including the following: 1) Philip Morris's "Smoke-free Israel Vision"; 2) the harm-reduction claim; 3) the proposition of a different regulation for "non-combustible products"; 4) attempts to tax IQOS at a different rate from that applicable to cigarettes; and 5) catchy advertising slogans (e.g., No fire/No smoke/No ash) [94].

Liber reported that, in most of the countries where HTPs were sold, these products had received tax advantages and its tax rates were lower than those of conventional cigarettes [95]. The differences between regulations for traditional cigarettes and HTPs can also be seen in the packaging of these products. For example, in Italy, health warnings are required to cover only $30 \%$ of the HTP packing in contrast to the traditional cigarette packing where warnings are required to cover $65 \%$ of cigarette packs [3]. In South Korea, the IQOS tobacco stick packs only have labels warning about nicotine addiction, without showing various negative consequences of smoking [4]. Moreover, the IQOS classification as a variant of e-cigarettes implies taxation and, in Korea, taxes on IQOS tobacco sticks are only half of that of traditional cigarettes [4]. In Israel, IQOS is taxed at the same rate as cigarettes [94].

Kreitzberg et al. identified 12774 posts and comments related to IQOS on Instagram (a photo and video-sharing social networking service) [96]. The analysis of the IQOS users' behavior in social media has shown that they are customizing IQOS devices and accessories dedicated to HTPs [96]. Sharing content related to the use of IQOS in social media, such as Instagram (photos when using the device or photos of customized devices), is used to build a community identified by such hashtags as \#IQOSFamily or \#IQOSFriends. Kreitzberg et al. suggested that Instagram might increase the social acceptability of tobacco use and, due to this fact, there should be an age restriction on the content promoting HTPs [96].

Furthermore, in many countries, heated tobacco products may be used in public places, in contrast to traditional cigarettes. All these activities have the potential to change social norms and attitudes towards tobacco use, and suggest to the public that HTPs are a safe form of tobacco use. Elias and Ling emphasized the key role of respected health leaders in shaping public attitudes towards novel tobacco products and their impact on the commercial fate of HTPs [97]. The authors encouraged public health experts to carefully formulate opinions, bearing in mind the past experience with the industry-backed "safer tobacco products," such as filtered and low-tar cigarettes, which served to undermine and delay the global tobacco control efforts [97]. Lempert and Glantz pointed out legal uncertainties regarding HTPs, especially electronic devices used to heat up tobacco sticks [98]. The authors concluded that in the USA and parties to the WHO Framework Convention on Tobacco Control (FCTC) all components of HTPs should be regulated at least as stringently as tobacco products and should be subject to all tobacco control laws that apply to other tobacco products [98]. 


\section{DISCUSSION}

The heated tobacco smoking technology has become increasingly popular $[6,79]$. The most popular HTP product - IQOS from PMI - is widely available in 33 countries worldwide, including 21 European countries [93]. Other popular HTPs - glo and Ploom TECH - are also gaining new markets [6]. The source of the aerosol is a tobacco stick made of processed tobacco $[12,13]$. Tobacco sticks are available in multiple flavors $[10,20]$. The variety of flavors, and especially the introduction of sweet fruit variants of tobacco sticks, may encourage young people to reach for HTPs because of their attractive taste. The chemical composition of HTP tobacco sticks differs from traditional cigarettes [22]. However, both of them have a comparable nicotine concentration $[9,21]$. Therefore, the levels of nicotine contained in the HTP aerosol have been $70-80 \%$ as those of conventional combustion cigarettes [15,27,29,33], based on the results of both independent and industry studies. This finding may suggest that HTPs were launched in response to the dissatisfaction with the lack of rapid nicotine delivery by ecigarettes. However, further research is needed to describe the profile and characteristics of HTP users.

According to the tobacco industry data, aerosols formed during the heating process have around $90-95 \%$ lower levels of toxicants than conventional cigarette smoke [13$15,23,24]$. Independent studies have confirmed that the concentration of chemical compounds generated by HTPs is lower than that generated by traditional cigarettes $[27,28,33]$. However, toxic compounds are not completely removed from the HTP aerosol [7,19,25-35]. The results of independent studies have shown that IQOS emit substantially lower levels of carbonyls and submicronic particles than a commercial cigarette but higher levels than an e-cigarette $[25,26,28]$. The emission of reactive oxygen species during IQOS use points to potentially harmful effects of IQOS use, such as cancer or pulmonary diseases [38]. Moreover, an independent review of preclinical and clinical data on IQOS has revealed the possible hepa- totoxicity associated with IQOS use [70]. Chun et al. suggested that HTP use might have unexpected organ toxicity not observed when smoking traditional cigarettes [70]. Following the manufacturer recommendations, especially proper cleaning of the device after each 20 tobacco sticks seems to be crucial to provide proper thermal regulation and reduce emissions of harmful substances. Most of the research regarding the chemical composition of generated aerosol was carried out on brand new, never used devices [39-54]. Independent researchers showed that the use of 1 IQOS tobacco stick left a significant amount of debris, fluid, and fragments of cast-leaf in the device holder [8]. It can be assumed that the lack of proper cleaning can lead to the accumulation of undesirable substances in the holder, influencing the heating conditions and chemical composition of the generated aerosol.

The tobacco industry has performed multiple studies regarding health consequences of HTP use. The results of in vitro and in vivo studies indicate that HTP aerosols have lower toxicity and no new hazards compared to conventional cigarette smoke [39-54]. The results of humanbased studies also suggest that switching from conventional cigarettes to IQOS or glo leads to reductions in exposure to smoke toxicants in a manner comparable to quitting tobacco use [74-78]. However, there have been no independent studies regarding short-term and longterm health consequences of HTP use.

Data provided by the tobacco industry did not convince the leading health organizations to recognize HTPs as "reduced risk products" [99-101]. In December 2016, PMI applied to the FDA (U.S. Food and Drug Administration) to consider IQOS as a modified risk tobacco product [83]. In January 2018, the FDA Tobacco Products Scientific Advisory Committee concluded that there was no conclusive scientific evidence that IQOS use was less risky than continuing tobacco smoking and PMI should not claim that IQOS use cut the risk of tobacco-related diseases [86,102]. Furthermore, the FDA experts were not convinced that 
smokers would use IQOS alone and stated that there was a high to medium risk of dual use of IQOS and conventional cigarettes [86,102].

According to the World Health Organization (WHO) statement, there is no evidence that HTPs are less harmful than conventional cigarettes [99]. The WHO has also emphasized that conclusions about the HTP ability to assist with quitting smoking cannot yet be drawn. The WHO has concluded that all forms of tobacco use are harmful and new tobacco products should be regulated under the WHO Framework Convention on Tobacco Control (FCTC) [99]. The European Respiratory Society (ERS) has stated that, as with regular tobacco smoking, heated tobacco products are addictive and carcinogenic to humans [100]. According to the ERS statement, there is no evidence that heated tobacco products are efficient tools to aid in smoking cessation. Moreover, the ERS cites some strong evidence suggesting that studies performed or sponsored by tobacco industry companies cannot be trusted [100]. The ERS has concluded that it cannot recommend any products which can be harmful to the lungs and human health [100].

A more liberal position is presented by Public Health England (PHE) [101]. This organization has concluded that available evidence suggests that heated tobacco products may be considerably less harmful than conventional cigarettes, but more harmful than e-cigarettes [101]. Despite this fact, PHE emphasizes the urgent need to provide more research independent of commercial interests [101].

The prevalence of HTP use is constantly growing, especially among current cigarette or e-cigarette smokers [6]. Such a high interest in HTPs among current smokers may pose a risk of dual use in this group. In many countries, the advertising and promotion of HTPs are not banned [3,98]. The marketing strategies and promotion of these products, such as fancy concept stores, brand ambassadors, and free samples testing, can support the increase in the number of HTP users [4,92,93]. Like e-cigarettes [103,104], HTPs are advertised via the Internet and social media [92-94]. Tobacco companies use dedicated hashtags and advertising slogans to promote HTPs on their websites [96]. The use of social media for the promotion of HTPs can make it more difficult to monitor the marketing activities which may contradict the WHO Framework Convention on Tobacco Control.

Current knowledge on HTP exposures and health effects is often based on data provided by the tobacco industry ( $52 \%$ of identified studies). There is a need for future independent research, especially human-based studies assessing short-term as well as long-term health effects of HTP use. Future studies will provide more information about passive HTP smoking and the impact of HTP secondhand smoke on bystanders, which will be crucial to implement proper regulations regarding HTPs, especially HTP use in public places. Currently, there is no evidence that HTPs can be used as an effective tool for smoking cessation. This topic also needs further investigation.

There are a few limitations to this study. This review was restricted to peer-reviewed articles available in English. Most of them focused only on data from 5 countries, which limits the external validity of this research. There was also substantial variation in the study designs of in vitro and in vivo studies, especially the conditions of exposure and the length of follow up. Sample sizes also varied substantially between studies. Nevertheless, this study is the most up-todate systematic review regarding heated tobacco products and addresses several different aspects of HTP use.

\section{CONCLUSIONS}

Heated tobacco products are gradually gaining in popularity. A chemical analysis of aerosols has revealed that heated tobacco products release lower levels of toxic chemicals compared to conventional cigarettes. However, toxic compounds are not completely removed from the HTP aerosol and these products are still not risk-free. The nicotine levels delivered to the aerosol by heated tobacco products were almost the same as those of conventional combustion. Health consequences of HTPs as well as their role in 
smoking aid are unknown. Among the currently available data on HTPs, most papers $(52 \%)$ have been sponsored by the tobacco industry. There is a need for the future independent and standardized investigations of the potential health effects associated with heated tobacco use and HTP potential in smoking cessation aid.

\section{REFERENCES}

1. Caputi TL. Industry watch: heat-not-burn tobacco products are about to reach their boiling point. Tob Control. 2016;26(5): 609-10, https://doi.org/10.1136/tobaccocontrol-2016-053264.

2. Liu X, Lugo A, Spizzichino L, Tabuchi T, Gorini G, Gallus S. Heat-Not-Burn Tobacco Products Are Getting Hot in Italy. J Epidemiol. 2018;28(5):274-5, https://doi.org/10.2188/jea.JE 20180040.

3. Liu X, Lugo A, Spizzichino L, Tabuchi T, Pacifici R, Gallus S. Heat-not-burn tobacco products: concerns from the Italian experience. Tob Control. 2019;28(1):113-4, https://doi. org/10.1136/tobaccocontrol-2017-054054.

4. Kim M. Philip Morris International introduces new heatnot-burn product, IQOS, in South Korea. Tob Control. 2018;27(e1):e76-8, https://doi.org/10.1136/tobaccocontrol2017-053965.

5. Tabuchi T, Kiyohara K, Hoshino T, Bekki K, Inaba Y, Kunugita N. Awareness and use of electronic cigarettes and heat-notburn tobacco products in Japan. Addiction. 2016;111(4):70613, https://doi.org/10.1111/add.13231.

6. Tabuchi T, Gallus S, Shinozaki T, Nakaya T, Kunugita N, Colwell B. Heat-not-burn tobacco product use in Japan: its prevalence, predictors and perceived symptoms from exposure to secondhand heat-not-burn tobacco aerosol. Tob Control. 2018;27(e1):e25-33, https://doi.org/10.1136/tobaccocontrol2017-053947.

7. Uchiyama S, Noguchi M, Takagi N, Hayashida H, InabaY, Ogura H, et al. Simple Determination of Gaseous and Particulate Compounds Generated from Heated Tobacco Products. Chem Res Toxicol. 2018;31(7):585-93, https://doi. org/10.1021/acs.chemrestox.8b00024.
8. Davis B, Williams M, Talbot P. iQOS: evidence of pyrolysis and release of a toxicant from plastic. Tob Control. 2019;28(1): 34-41, https://doi.org/10.1136/tobaccocontrol-2017-054104.

9. Farsalinos KE, Yannovits N, Sarri T, Voudris V, Poulas K. Nicotine Delivery to the Aerosol of a Heat-Not-Burn Tobacco Product: Comparison With a Tobacco Cigarette and E-Cigarettes. Nicotine Tob Res. 2018;20(8):1004-9, https:// doi.org/10.1093/ntr/ntx138.

10. Proctor C. Assessment of tobacco heating product THP1.0. Part 1: Series introduction. Regul Toxicol Pharmacol. 2018; 93:1-3, https://doi.org/10.1016/j.yrtph.2017.09.010.

11. Eaton D, Jakaj B, Forster M, Nicol J, Mavropoulou E, Scott K, et al. Assessment of tobacco heating product THP1.0. Part 2: Product design, operation and thermophysical characterisation. Regul Toxicol Pharmacol. 2018;93:4-13, https://doi.org/10.1016/j.yrtph.2017.09.009.

12. Yuki D, Sakaguchi C, Kikuchi A, Futamura Y. Pharmacokinetics of nicotine following the controlled use of a prototype novel tobacco vapor product. Regul Toxicol Pharmacol. 2017;87:30-5, https://doi.org/10.1016/j.yrtph.2017.05.005.

13. Ichitsubo H, Kotaki M. Indoor air quality (IAQ) evaluation of a Novel Tobacco Vapor (NTV) product. Regul Toxicol Pharmacol. 2018;92:278-94, https://doi.org/10.1016/j.yrtph.2017.12.017.

14. Mitova MI, Campelos PB, Goujon-Ginglinger CG, Maeder S, Mottier N, Rouget EG, et al. Comparison of the impact of the Tobacco Heating System 2.2 and a cigarette on indoor air quality. Regul Toxicol Pharmacol. 2016;80:91-101, https://doi.org/10.1016/j.yrtph.2016.06.005.

15. Jaccard G, Tafin Djoko D, Moennikes O, Jeannet C, Kondylis A, Belushkin M. Comparative assessment of HPHC yields in the Tobacco Heating System THS2.2 and commercial cigarettes. Regul Toxicol Pharmacol. 2017;90:1-8, https://doi. org/10.1016/j.yrtph.2017.08.006.

16. Haswell LE, Corke S, Verrastro I, Baxter A, Banerjee A, Adamson J, et al. In vitro RNA-seq-based toxicogenomics assessment shows reduced biological effect of tobacco heating products when compared to cigarette smoke. Sci Rep. 2018;8(1):1145, https://doi.org/10.1038/s41598-018-19627-0. 
17. Crooks I, Neilson L, Scott K, Reynolds L, Oke T, Forster M, et al. Evaluation of flavourings potentially used in a heated tobacco product: Chemical analysis, in vitro mutagenicity, genotoxicity, cytotoxicity and in vitro tumour promoting activity. Food Chem Toxicol. 2018;118:940-52, https://doi. org/10.1016/j.fct.2018.05.058.

18. Ishikawa S, Matsumura K, Kitamura N, Ishimori K, Takanami Y, Ito S. Application of a direct aerosol exposure system for the assessment of biological effects of cigarette smoke and novel tobacco product vapor on human bronchial epithelial cultures. Regul Toxicol Pharmacol. 2018;96:85-93, https://doi.org/10.1016/j.yrtph.2018.05.004.

19. Phillips BW, Schlage WK, Titz B, Kogel U, Sciuscio D, Martin F, et al. A 90-day OECD TG 413 rat inhalation study with systems toxicology endpoints demonstrates reduced exposure effects of the aerosol from the carbon heated tobacco product version 1.2 (CHTP1.2) compared with cigarette smoke. I. Inhalation exposure, clinical pathology and histopathology. Food Chem Toxicol. 2018;116:388-413, https:// doi.org/10.1016/j.fct.2018.04.015.

20. Pacitto A, Stabile L, Scungio M, Rizza V, Buonanno G. Characterization of airborne particles emitted by an electrically heated tobacco smoking system. Environ Pollut. 2018;240: 248-54, https://doi.org/10.1016/j.envpol.2018.04.137.

21. Bekki K, Inaba Y, Uchiyama S, Kunugita N. Comparison of Chemicals in Mainstream Smoke in Heat-not-burn Tobacco and Combustion Cigarettes. J UOEH. 2017;39(3):201-7, https://doi.org/10.7888/juoeh.39.201.

22. Smith MR, Clark B, Lüdicke F, Schaller JP, Vanscheeuwijck P, Hoeng J, et al. Evaluation of the Tobacco Heating System 2.2. Part 1: Description of the system and the scientific assessment program. Regul Toxicol Pharmacol. 2016;81: S17-26, https://doi.org/10.1016/j.yrtph.2016.07.006.

23. Pratte P, Cosandey S, Goujon Ginglinger C. Investigation of solid particles in the mainstream aerosol of the Tobacco Heating System THS2.2 and mainstream smoke of a 3R4F reference cigarette. Hum Exp Toxicol. 2017;36(11):1115-20, https://doi.org/10.1177/0960327116681653.
24. Buratto R, Correia D, Parel M, Crenna M, Bilger M, Debrick A. Determination of eight carbonyl compounds in aerosols trapped in phosphate buffer saline solutions to support in vitro assessment studies. Talanta. 2018;184:42-9, https://doi.org/10.1016/j.talanta.2018.02.048.

25. Protano C, Manigrasso M, Avino P, Sernia S, Vitali M. Second-hand smoke exposure generated by new electronic devices (IQOS $®$ and e-cigs) and traditional cigarettes: submicron particle behaviour in human respiratory system. Ann Ig. 2016;28(2):109-12, https://doi.org/10.7416/ai.2016.2089.

26. Protano C, Manigrasso M, Avino P, Vitali M. Second-hand smoke generated by combustion and electronic smoking devices used in real scenarios: Ultrafine particle pollution and age-related dose assessment. Environ Int. 2017;107:190-5, https://doi.org/10.1016/j.envint.2017.07.014.

27. Li X, Luo Y, Jiang X, Zhang H, Zhu F, Hu S, et al. Chemical Analysis and Simulated Pyrolysis of Tobacco Heating System 2.2 Compared to Conventional Cigarettes. Nicotine Tob Res. 2019;21(1):111-8, https://doi.org/10.1093/ntr/nty005.

28. Farsalinos KE, Yannovits N, Sarri T, Voudris V, Poulas K, Leischow SJ. Carbonyl emissions from a novel heated tobacco product (IQOS): comparison with an e-cigarette and a tobacco cigarette. Addiction. 2018;113(11):2099-106, https:// doi.org/10.1111/add.14365.

29. Auer R, Concha-Lozano N, Jacot-Sadowski I, Cornuz J, Berthet A. Heat-Not-Burn Tobacco Cigarettes: Smoke by Any Other Name. JAMA Intern Med. 2017;177(7):1050-2, https://doi.org/10.1001/jamainternmed.2017.1419.

30. Auer R, Cornuz J, Berthet A. Perplexing Conclusions Concerning Heat-Not-Burn Tobacco Cigarettes-Reply. JAMA Intern Med. 2017;177(11):1699-700, https://doi.org/10.1001/ jamainternmed.2017.5861.

31. Caruso M, Polosa R. Perplexing Conclusions Concerning Heat-Not-Burn Tobacco Cigarettes. JAMA Intern Med. 2017;177(11):1699, https://doi.org/10.1001/jamaintern med.2017.5843.

32. Maeder S, Peitsch MC. Perplexing Conclusions Concerning Heat-Not-Burn Tobacco Cigarettes. JAMA Intern Med. 
2017;177(11):1698-9, https://doi.org/10.1001/jamaintern med.2017.5840.

33. Mallock N, Böss L, Burk R, Danziger M, Welsch T, Hahn H, et al. Levels of selected analytes in the emissions of "heat not burn" tobacco products that are relevant to assess human health risks. Arch Toxicol. 2018;92(6):2145-9, https:// doi.org/10.1007/s00204-018-2215-y.

34. Ruprecht AA, De Marco C, Saffari A, Pozzi P, Mazza R, Veronese $\mathrm{C}$, et al. Environmental pollution and emission factors of electronic cigarettes, heat-not-burn tobacco products, and conventional cigarettes. Aerosol Sci Technol. 2017;51:(6):674-84, https://doi.org/10.1080/02786826.2017. 1300231.

35. Ruprecht AA, De Marco C, Saffari A, Pozzi P, Mazza R, Veronese $\mathrm{C}$, et al. Erratum to: Environmental pollution and emission factors of electronic cigarettes, heat-not-burn tobacco products, and conventional cigarettes. Aerosol Sci Technol. 2017;51:(11):1332, https://doi.org/10.1080/0278682 6.2017.1397236.

36. Brossard P, Weitkunat R, Poux V, Lama N, Haziza C, Picavet $\mathrm{P}$, et al. Nicotine pharmacokinetic profiles of the Tobacco Heating System 2.2, cigarettes and nicotine gum in Japanese smokers. Regul Toxicol Pharmacol. 2017;89:193-9, https:// doi.org/10.1016/j.yrtph.2017.07.032.

37. Leigh NJ, Palumbo MN, Marino AM, O'Connor RJ, Goniewicz ML. Tobacco-specific nitrosamines (TSNA) in heated tobacco product IQOS. Tob Control. 2018;27(Suppl 1):s37-8, https://doi.org/10.1136/tobaccocontrol-2018-05 4318.

38. Salman R, Talih S, El-Hage R, Haddad C, Karaoghlanian N, El-Hellani A, et al. Free-Base and Total Nicotine, Reactive Oxygen Species, and Carbonyl Emissions From IQOS, a Heated Tobacco Product. Nicotine Tob Res. 2018, https:// doi.org/10.1093/ntr/nty235.

39. Dayan AD. Investigating a toxic risk (self-inflicted) the example of conventional and advanced studies of a novel Tobacco Heating System. Regul Toxicol Pharmacol. 2016;81:S15-6, https://doi.org/10.1016/j.yrtph.2016.07.020.
40. Schaller JP, Keller D, Poget L, Pratte P, Kaelin E, McHugh D, et al. Evaluation of the Tobacco Heating System 2.2. Part 2: Chemical composition, genotoxicity, cytotoxicity, and physical properties of the aerosol. Regul Toxicol Pharmacol. 2016;81:S27-47, https://doi.org/10.1016/j.yrtph.2016.10.001.

41. Schaller JP, Pijnenburg JP, Ajithkumar A, Tricker AR. Evaluation of the Tobacco Heating System 2.2. Part 3: Influence of the tobacco blend on the formation of harmful and potentially harmful constituents of the Tobacco Heating System 2.2 aerosol. Regul Toxicol Pharmacol. 2016;81:S48-58, https://doi.org/10.1016/j.yrtph.2016.10.016.

42. Wong ET, Kogel U, Veljkovic E, Martin F, Xiang Y, Boue S, et al. Evaluation of the Tobacco Heating System 2.2. Part 4: 90-day OECD 413 rat inhalation study with systems toxicology endpoints demonstrates reduced exposure effects compared with cigarette smoke. Regul Toxicol Pharmacol. 2016;81:S59-81, https://doi.org/10.1016/j.yrtph.2016.10.015.

43. Sewer A, Kogel U, Talikka M, Wong ET, Martin F, Xiang Y, et al. Evaluation of the Tobacco Heating System 2.2 (THS2.2). Part 5: microRNA expression from a 90-day rat inhalation study indicates that exposure to THS2.2 aerosol causes reduced effects on lung tissue compared with cigarette smoke. Regul Toxicol Pharmacol. 2016;81:S82-92, https://doi.org/10.1016/j.yrtph.2016.11.018.

44. Oviedo A, Lebrun S, Kogel U, Ho J, Tan WT, Titz B, et al. Evaluation of the Tobacco Heating System 2.2. Part 6: 90-day OECD 413 rat inhalation study with systems toxicology endpoints demonstrates reduced exposure effects of a mentholated version compared with mentholated and nonmentholated cigarette smoke. Regul Toxicol Pharmacol. 2016;81:S93-122, https://doi.org/10.1016/j.yrtph.2016.11.004.

45. Kogel U, Titz B, Schlage WK, Nury C, Martin F, Oviedo A, et al. Evaluation of the Tobacco Heating System 2.2. Part 7: Systems toxicological assessment of a mentholated version revealed reduced cellular and molecular exposure effects compared with mentholated and non-mentholated cigarette smoke. Regul Toxicol Pharmacol. 2016;81:S123-38, https:// doi.org/10.1016/j.yrtph.2016.11.001. 
46. Haziza C, de La Bourdonnaye G, Skiada D, Ancerewicz J, Baker G, Picavet P, et al. Evaluation of the Tobacco Heating System 2.2. Part 8:5-Day randomized reduced exposure clinical study in Poland. Regul Toxicol Pharmacol. 2016;81:S13950, https://doi.org/10.1016/j.yrtph.2016.11.003.

47. Martin F, Talikka M, Ivanov NV, Haziza C, Hoeng J, Peitsch MC. Evaluation of the tobacco heating system 2.2. Part 9: Application of systems pharmacology to identify exposure response markers in peripheral blood of smokers switching to THS2.2. Regul Toxicol Pharmacol. 2016;81:S151-7, https://doi.org/10.1016/j.yrtph.2016. 11.011.

48. Forster M, Fiebelkorn S, Yurteri C, Mariner D, Liu C, Wright $\mathrm{C}$, et al. Assessment of novel tobacco heating product THP1.0. Part 3: Comprehensive chemical characterisation of harmful and potentially harmful aerosol emissions. Regul Toxicol Pharmacol. 2018;93:14-33, https://doi.org/10.1016/ j.yrtph.2017.10.006.

49. Forster M, McAughey J, Prasad K, Mavropoulou E, Proctor C. Assessment of tobacco heating product THP1.0. Part 4: Characterisation of indoor air quality and odour. Regul Toxicol Pharmacol. 2018;93:34-51, https://doi.org/10.1016/ j.yrtph.2017.09.017.

50. Jaunky T, Adamson J, Santopietro S, Terry A, Thorne D, Breheny D, et al. Assessment of tobacco heating product THP1.0. Part 5: In vitro dosimetric and cytotoxic assessment. Regul Toxicol Pharmacol. 2018;93:52-61, https://doi. org/10.1016/j.yrtph.2017.09.016.

51. Taylor M, Thorne D, Carr T, Breheny D, Walker P, Proctor $\mathrm{C}$, et al. Assessment of novel tobacco heating product THP1.0. Part 6: A comparative in vitro study using contemporary screening approaches. Regul Toxicol Pharmacol. 2018;93:62-70, https://doi.org/10.1016/j.yrtph. 2017.08.016.

52. Thorne D, Breheny D, Proctor C, Gaca M. Assessment of novel tobacco heating product THP1.0. Part 7: Comparative in vitro toxicological evaluation. Regul Toxicol Pharmacol. 2018;93:71-83, https://doi.org/10.1016/j.yrtph.2017.08.017.
53. Gee J, Prasad K, Slayford S, Gray A, Nother K, Cunningham A, et al. Assessment of tobacco heating product THP1.0. Part 8: Study to determine puffing topography, mouth level exposure and consumption among Japanese users. Regul Toxicol Pharmacol. 2018;93:84-91, https://doi. org/10.1016/j.yrtph.2017.08.005.

54. Murphy J, Liu C, McAdam K, Gaça M, Prasad K, Camacho O, et al. Assessment of tobacco heating product THP1.0. Part 9: The placement of a range of next-generation products on an emissions continuum relative to cigarettes via pre-clinical assessment studies. Regul Toxicol Pharmacol. 2018;93:92-104, https://doi.org/10.1016/j.yrtph.2017.10.001.

55. Poussin C, Laurent A, Peitsch MC, Hoeng J, De Leon H. Systems toxicology-based assessment of the candidate modified risk tobacco product THS2.2 for the adhesion of monocytic cells to human coronary arterial endothelial cells. Toxicology. 2016;339:73-86, https://doi.org/10.1016/j.tox.2015.11.007. 56. Van der Toorn M, Frentzel S, De Leon H, Goedertier D, Peitsch MC, Hoeng J. Aerosol from a candidate modified risk tobacco product has reduced effects on chemotaxis and transendothelial migration compared to combustion of conventional cigarettes. Food Chem Toxicol. 2015;86:81-7, https://doi.org/10.1016/j.fct.2015.09.016.

57. Iskandar AR, Mathis C, Schlage WK, Frentzel S, Leroy P, Xiang Y, et al. A systems toxicology approach for comparative assessment: Biological impact of an aerosol from a candidate modified-risk tobacco product and cigarette smoke on human organotypic bronchial epithelial cultures. Toxicol In Vitro. 2017;39:29-51, https://doi.org/10.1016/ j.tiv.2016.11.009.

58. Iskandar AR, Mathis C, Martin F, Leroy P, Sewer A, Majeed S, et al. 3-D nasal cultures: Systems toxicological assessment of a candidate modified-risk tobacco product. ALTEX. 2017;34(1):23-48, https://doi.org/10.14573/altex. 1605041.

59. Zanetti F, Titz B, Sewer A, Lo Sasso G, Scotti E, Schlage WK, et al. Comparative systems toxicology analysis of cigarette smoke and aerosol from a candidate modified risk tobacco 
product in organotypic human gingival epithelial cultures: A 3-day repeated exposure study. Food Chem Toxicol. 2017;101:15-35, https://doi.org/10.1016/j.fct.2016.12.027.

60. Zhao X, Zanetti F, Majeed S, Pan J, Malmstrom H, Peitsch MC, et al. Effects of cigarette smoking on color stability of dental resin composites. Am J Dent. 2017;30(6):316-22. 61. Malinska D, Szymański J, Patalas-Krawczyk P, Michalska B, Wojtala A, Prill M, et al. Assessment of mitochondrial function following short- and long-term exposure of human bronchial epithelial cells to total particulate matter from a candidate modified-risk tobacco product and reference cigarettes. Food Chem Toxicol. 2018;115:1-12, https:/doi. org/10.1016/j.fct.2018.02.013.

62. Van der Toorn M, Sewer A, Marescotti D, Johne S, Baumer K, Bornand D, et al. The biological effects of long-term exposure of human bronchial epithelial cells to total particulate matter from a candidate modified-risk tobacco product. Toxicol In Vitro. 2018;50:95-108, https://doi.org/10.1016/ j.tiv.2018.02.019.

63. Takahashi Y, Kanemaru Y, Fukushima T, Eguchi K, Yoshida S, Miller-Holt J, et al. Chemical analysis and in vitro toxicological evaluation of aerosol from a novel tobacco vapor product: A comparison with cigarette smoke. Regul Toxicol Pharmacol. 2018;92:94-103, https://doi.org/10.1016/j.yrtph.2017.11.009.

64. Szostak J, Boué S, Talikka M, Guedj E, Martin F, Phillips B, et al. Aerosol from Tobacco Heating System 2.2 has reduced impact on mouse heart gene expression compared with cigarette smoke. Food Chem Toxicol. 2017;101:157-67, https:// doi.org/10.1016/j.fct.2017.01.013.

65. Lo Sasso G, Titz B, Nury C, Boué S, Phillips B, Belcastro V, et al. Effects of cigarette smoke, cessation and switching to a candidate modified risk tobacco product on the liver in Apoe-/- mice - a systems toxicology analysis. Inhal Toxicol. 2016;28(5):226-40, https://doi.org/10.3109/08958378.2016. 1150368.

66. Phillips B, Veljkovic E, Boué S, Schlage WK, Vuillaume G, Martin F, et al. An 8-Month Systems Toxicology Inhalation/Cessation Study in Apoe-/- Mice to Investigate
Cardiovascular and Respiratory Exposure Effects of a Candidate Modified Risk Tobacco Product, THS 2.2, Compared With Conventional Cigarettes. Toxicol Sci. 2016;149(2):41132, https://doi.org/10.1093/toxsci/kfv243.

67. Phillips B, Veljkovic E, Boué S, Schlage WK, Vuillaume G, Martin F, et al. Erratum to: An 8-Month Systems Toxicology Inhalation/Cessation Study in Apoe-/- Mice to Investigate Cardiovascular and Respiratory Exposure Effects of a Candidate Modified Risk Tobacco Product, THS 2.2, Compared With Conventional Cigarettes. Toxicol Sci. 2016;151(2):4624, https://doi.org/10.1093/toxsci/kfw062.

68. Titz B, Boué S, Phillips B, Talikka M, Vihervaara T, Schneider T, et al. Effects of Cigarette Smoke, Cessation, and Switching to Two Heat-Not-Burn Tobacco Products on Lung Lipid Metabolism in C57BL/6 and Apoe-/- MiceAn Integrative Systems Toxicology Analysis. Toxicol Sci. 2016;149(2):441-57, https://doi.org/10.1093/toxsci/kfv244.

69. Velicer C, St Helen G, Glantz SA. Tobacco papers and tobacco industry ties in regulatory toxicology and pharmacology. J Public Health Policy. 2018;39(1):34-48, https://doi. org/10.1057/s41271-017-0096-6.

70. Chun L, Moazed F, Matthay M, Calfee C, Gotts J. Possible hepatotoxicity of IQOS. Tob Control. 2018;27(Suppl 1):s3940, https://doi.org/10.1136/tobaccocontrol-2018-054320.

71. Nabavizadeh P, Liu J, Havel CM, Ibrahim S, Derakhshandeh R, Jacob Iii P, et al. Vascular endothelial function is impaired by aerosol from a single IQOS HeatStick to the same extent as by cigarette smoke. Tob Control. 2018;27(Suppl 1): s13-9, https://doi.org/10.1136/tobaccocontrol-2018-054325.

72. Leigh NJ, Tran PL, O'Connor RJ, Goniewicz ML. Cytotoxic effects of heated tobacco products (HTP) on human bronchial epithelial cells. Tob Control. 2018;27(Suppl 1):s26-9, https://doi.org/10.1136/tobaccocontrol-2018-054317.

73. Picavet P, Haziza C, Lama N, Weitkunat R, Lüdicke F. Comparison of the Pharmacokinetics of Nicotine Following Single and Ad Libitum Use of a Tobacco Heating System or Combustible Cigarettes. Nicotine Tob Res. 2016;18(5):55763, https://doi.org/10.1093/ntr/ntv220. 
74. Lüdicke F, Picavet P, Baker G, Haziza C, Poux V, Lama N, et al. Effects of Switching to the Tobacco Heating System 2.2 Menthol, Smoking Abstinence, or Continued Cigarette Smoking on Biomarkers of Exposure: A Randomized, Controlled, Open-Label, Multicenter Study in Sequential Confinement and Ambulatory Settings (Part 1). Nicotine Tob Res. 2018;20(2):161-72, https://doi.org/10.1093/ntr/ntw287.

75. Lüdicke F, Picavet P, Baker G, Haziza C, Poux V, Lama N, et al. Effects of Switching to the Menthol Tobacco Heating System 2.2, Smoking Abstinence, or Continued Cigarette Smoking on Clinically Relevant Risk Markers: A Randomized, Controlled, Open-Label, Multicenter Study in Sequential Confinement and Ambulatory Settings (Part 2). Nicotine Tob Res. 2018;20(2):173-82, https://doi.org/10.1093/ntr/ ntx028.

76. Lüdicke F, Baker G, Magnette J, Picavet P, Weitkunat R. Reduced Exposure to Harmful and Potentially Harmful Smoke Constituents With the Tobacco Heating System 2.1. Nicotine Tob Res. 2017;19(2):168-75, https://doi.org/10.1093/ntr/ntw164.

77. Haziza C, de La Bourdonnaye G, Merlet S, Benzimra M, Ancerewicz J, Donelli A, et al. Assessment of the reduction in levels of exposure to harmful and potentially harmful constituents in Japanese subjects using a novel tobacco heating system compared with conventional cigarettes and smoking abstinence: A randomized controlled study in confinement. Regul Toxicol Pharmacol. 2016;81:489-99, https://doi. org/10.1016/j.yrtph.2016.09.014.

78. Gale N, McEwan M, Eldridge AC, Fearon IM, Sherwood N, Bowen E, et al. Changes in Biomarkers of Exposure on Switching From a Conventional Cigarette to Tobacco Heating Products: A Randomized, Controlled Study in Healthy Japanese Subjects. Nicotine Tob Res. 2018:1-8, https://doi.org/10.1093/ntr/nty104.

79. Adriaens K, Gucht DV, Baeyens F. IQOSTM vs. e-Cigarette vs. Tobacco Cigarette: A Direct Comparison of Short-Term Effects after Overnight-Abstinence. Int J Environ Res Public Health. 2018;15(12):E2902, https://doi.org/10.3390/ ijerph15122902.
80. Stephens WE. Comparing the cancer potencies of emissions from vapourised nicotine products including e-cigarettes with those of tobacco smoke. Tob Control. 2018;27:10-7, https://doi.org/10.1136/tobaccocontrol-2017-053808.

81. Kamada T, Yamashita T, Tomioka H. Acute eosinophilic pneumonia following heat-not-burn cigarette smoking. Respirol Case Rep. 2016;4(6):e00190, https://doi.org/10.1002/ rer2.190.

82. Aokage T, Tsukahara K, Fukuda Y, Tokioka F, Taniguchi A, Naito $\mathrm{H}$, et al. Heat-not-burn cigarettes induce fulminant acute eosinophilic pneumonia requiring extracorporeal membrane oxygenation. Respir Med Case Rep. 2018;26:8790, https://doi.org/10.1016/j.rmcr.2018.12.002.

83. Moazed F, Chun L, Matthay MA, Calfee CS, Gotts J. Assessment of industry data on pulmonary and immunosuppressive effects of IQOS. Tob Control. 2018;27(Suppl 1):s20-5, https://doi.org/10.1136/tobaccocontrol-2018-054296.

84. Glantz SA. PMI's own in vivo clinical data on biomarkers of potential harm in Americans show that IQOS is not detectably different from conventional cigarettes. Tob Control. 2018;27(Suppl 1):s9-12, https://doi.org/10.1136/tobaccocontrol-2018-054413.

85. Brose LS, Simonavicius E, Cheeseman H. Awareness and Use of "Heat-not-burn" Tobacco Products in Great Britain. Tob Regul Sci. 2018;4(2):44-50, https://doi.org/10.18001/ TRS.4.2.4.

86. Kim J, Yu H, Lee S, Paek YJ. Awareness, experience and prevalence of heated tobacco product, IQOS, among young Korean adult. Tob Control. 2018;27:s74-7, https://doi.org/10. 1136/tobaccocontrol-2018-054390.

87. Nyman AL, Weaver SR, Popova L, Pechacek TF, Huang J, Ashley DL, et al. Awareness and use of heated tobacco products among US adults, 2016-2017. Tob Control. 2018;27(Suppl 1): s55-61, https://doi.org/10.1136/tobaccocontrol-2018-054323.

88. Marynak KL, Wang TW, King BA, Agaku IT, Reimels EA, Graffunder CM. Awareness and Ever Use of "Heat-Not-Burn" Tobacco Products Among U.S. Adults, 2017. Am J Prev Med. 2018;55(4):551-4, https://doi.org/10.1016/j.amepre.2018.04.031. 
89. Miyazaki Y, Tabuchi T. Educational gradients in the use of electronic cigarettes and heat-not-burn tobacco products in Japan. PLoS One. 2018;13(1):e0191008, https://doi. org/10.1371/journal.pone.0191008.

90. Caputi TL, Leas E, Dredze M, Cohen JE, Ayers JW. They're heating up: Internet search query trends reveal significant public interest in heat-not-burn tobacco products. PLoS One. 2017;12(10):e0185735, https://doi.org/10.1371/journal. pone. 0185735 .

91. Elias J, Dutra LM, St Helen G, Ling PM. Revolution or redux? Assessing IQOS through a precursor product. Tob Control. 2018;27(Suppl 1):s102-10, https://doi.org/10.1136/ tobaccocontrol-2018-054327.

92. Mathers A, Schwartz R, O'Connor S, Fung M, Diemert L. Marketing IQOS in a dark market. Tob Control. 2018;28(2): 237-8, https://doi.org/10.1136/tobaccocontrol-2017-054216.

93. Hair EC, Bennett M, Sheen E, Cantrell J, Briggs J, Fenn Z, et al. Examining perceptions about IQOS heated tobacco product: consumer studies in Japan and Switzerland. Tob Control. 2018;27(Suppl 1):s70-3, https://doi.org/10.1136/tobaccocontrol-2018-054322.

94. Rosen LJ, Kislev S. IQOS campaign in Israel. Tob Control. 2018;27(Suppl 1):s78-81, https://doi.org/10.1136/tobaccocon trol-2018-054619.

95. Liber AC. Heated tobacco products and combusted cigarettes: comparing global prices and taxes. Tob Control. 2018, https://doi.org/10.1136/tobaccocontrol-2018-054602.

96. Kreitzberg DS, Murthy D, Loukas A, Pasch KE. Heat not burn tobacco promotion on instagram. Addict Behav. 2019;91:112-8, https://doi.org/10.1016/j.addbeh.2018.09.003.

97. Elias J, Ling PM. Invisible smoke: third-party endorsement and the resurrection of heat-not-burn tobacco products. Tob Control. 2018;27(Suppl 1):s96-101, https://doi. org/10.1136/tobaccocontrol-2018-054433.

98. Lempert LK, Glantz SA. Heated tobacco product regulation under US law and the FCTC. Tob Control.
2018;27(Suppl 1):s118-25, https://doi.org/10.1136/tobaccocontrol-2018-054560.

99. World Health Organization [Internet]. Geneva: The Organization; 2018 [cited 2018 Dec 23]. Heated tobacco products (HTPs) information sheet. Available from: http://www. who.int/tobacco/publications/prod_regulation/heated-tobacco-products/en/.

100. European Respiratory Society [Internet]. Lausanne: The Organization; 2018 [cited 2018 Dec 23]. ERS position paper on heated tobacco products. Available from: https:// www.ersnet.org/the-society/news/ers-position-paper-onheated-tobacco-products.

101. Public Health England [Internet]. London: The Organization; 2018 [cited 2018 Dec 23]. Evidence review of e-cigarettes and heated tobacco products 2018: executive summary. Available from: https://www.gov.uk/government/ publications/e-cigarettes-and-heated-tobacco-products-evidence-review/evidence-review-of-e-cigarettes-and-heatedtobacco-products-2018-executive-summary.

102. McKelvey K, Popova L, Kim M, Lempert LK, Chaffee BW, Vijayaraghavan M, et al. IQOS labelling will mislead consumers. Tob Control. 2018;27(Suppl 1):s48-54, https://doi. org/10.1136/tobaccocontrol-2018-054333.

103. Vandewater EA, Clendennen SL, Hébert ET, Bigman G, Jackson CD, Wilkinson AV, et al. Whose Post Is It? Predicting E-cigarette Brand from Social Media Posts. Tob Regul Sci. 2018;4:30-43, https://doi.org/10.18001/TRS.4.2.3.

104. Collins L, Glasser AM, Abudayyeh H, Pearson JL, Villanti AC. E-Cigarette Marketing and Communication: How E-Cigarette Companies Market E-Cigarettes and the Public Engages with E-cigarette Information. Nicotine Tob Res. 2019;21(1):14-24, https://doi.org/10.1093/ntr/ntx284.

105. Moher D, Liberati A, Tetzlaff J, Altman DG, The PRISMA Group. Preferred Reporting Items for Systematic Reviews and Meta-Analyses: The PRISMA Statement. BMJ. 2009;339:b2535, https://www.bmj.com/content/339/bmj.b2535.

This work is available in Open Access model and licensed under a Creative Commons Attribution-NonCommercial 3.0 Poland License - http://creativecommons.org/ licenses/by-nc/3.0/pl/deed.en. 